Article

\title{
Stratospheric Aerosols from Major Volcanic Eruptions: A Composition-Climate Model Study of the Aerosol Cloud Dispersal and $e$-folding Time
}

\author{
Giovanni Pitari ${ }^{1}$ *, Glauco Di Genova ${ }^{1}$, Eva Mancini ${ }^{1}$, Daniele Visioni ${ }^{1}$, Ilaria Gandolfi ${ }^{1}$ \\ and Irene Cionni ${ }^{2}$ \\ 1 Department of Physical and Chemical Sciences, Università degli Studi dell'Aquila, L'Aquila 67100, Italy; \\ glauco.digenova@aquila.infn.it (G.D.G.); eva.mancini@aquila.infn.it (E.M.); \\ daniele.visioni@aquila.infn.it (D.V.); ilaria.gandolfi@aquila.infn.it (I.G.) \\ 2 Enea, Ente per le Nuove Tecnologie, l'Energia e l'Ambiente, Roma 00123, Italy; irene.cionni@enea.it \\ * Correspondence: gianni.pitari@aquila.infn.it; Tel.: +39-086-243-3074; Fax: +39-086-243-3033 \\ Academic Editor: Robert Talbot \\ Received: 10 March 2016; Accepted: 19 May 2016; Published: 26 May 2016
}

\begin{abstract}
Large explosive volcanic eruptions are capable of injecting considerable amounts of particles and sulfur gases above the tropopause, causing large increases in stratospheric aerosols. Five major volcanic eruptions after 1960 (i.e., Agung, St. Helens, El Chichón, Nevado del Ruiz and Pinatubo) have been considered in a numerical study conducted with a composition-climate coupled model including an aerosol microphysics code for aerosol formation and growth. Model results are compared between an ensemble of numerical simulations including volcanic aerosols and their radiative effects (VE) and a reference simulations ensemble (REF) with no radiative impact of the volcanic aerosols. Differences of VE-REF show enhanced diabatic heating rates; increased stratospheric temperatures and mean zonal westerly winds; increased planetary wave amplitude; and tropical upwelling. The impact on stratospheric upwelling is found to be larger when the volcanically perturbed stratospheric aerosol is confined to the tropics, as tends to be the case for eruptions which were followed by several months with easterly shear of the quasi-biennial oscillation (QBO), e.g., the Pinatubo case. Compared to an eruption followed by a period of westerly QBO, such easterly QBO eruptions are quite different, with meridional transport to mid- and high-latitudes occurring later, and at higher altitude, with a consequent decrease in cross-tropopause removal from the stratosphere, and therefore longer decay timescale. Comparing the model-calculated $e$-folding time of the volcanic aerosol mass during the first year after the eruptions, an increase is found from 8.1 and 10.3 months for El Chichón and Agung (QBO westerly shear), to 14.6 and 30.7 months for Pinatubo and Ruiz (QBO easterly shear). The corresponding $e$-folding time of the global-mean radiative flux changes goes from 9.1 and 8.0 months for El Chichón and Agung, to 28.7 and 24.5 months for Pinatubo and Ruiz.
\end{abstract}

Keywords: composition-climate model; explosive volcanic eruptions; sulfate aerosols; aerosol radiative efficiency; stratospheric dynamics; quasi-biennial oscillation

\section{Introduction}

Surface temperature records [1] have demonstrated that major volcanic eruptions reaching the stratosphere globally cool the surface by a few tenths of a degree. The stratospheric aerosol layer may also be perturbed by more moderate eruptions ( $\sim 0.5-3 \mathrm{Tg}-\mathrm{SO}_{2}$ injected in the upper troposphere and lower stratosphere [2]), with small but non-negligible impact on global surface temperatures [3]. These eruptions have contributed to the generally increasing levels of stratospheric aerosols between 2002 and 2010, as observed from measurements by satellite [4]; ground-based lidars [5,6]; and ground-based sun-photometers, lidar and balloons [7]. 
In addition to injecting considerable amounts of particles and sulfur gases above the tropopause, large explosive eruptions also significantly affect the planetary-scale transport of several other important stratospheric trace species. Perturbations of stratospheric dynamics result from both local stratospheric heating (with associated changes of temperature and zonal wind fields), as well as from climate changes following the increasing scattering of incoming solar radiation by the volcanic aerosols [8,9]; stratospheric dynamical perturbations may in turn affect surface climate [10]. Climate changes since the 1960s have also induced dynamical and temperature changes in the stratosphere, as well as the effects from elevated halogen loading, causing changes in the nature of the volcanic responses since the 1960s (e.g., when Mt. Agung erupted) compared to Pinatubo.

The radiatively forced changes of the stratospheric circulation during the first two years after the eruption of Mt. Pinatubo (June 1991) may help explain the observed declining growth rate of long-lived greenhouse gases (as $\mathrm{CH}_{4}$ and $\mathrm{N}_{2} \mathrm{O}$ ) [11-14], as a result of the increased mid- to high-latitude stratospheric downward fluxes. Since the stratosphere contains lower $\mathrm{CH}_{4}$ and $\mathrm{N}_{2} \mathrm{O}$ mixing ratios, a decline in the observed trends could result from a higher degree of exchange between the stratosphere and the troposphere [15]. Other important processes that may have affected the tropospheric abundance of $\mathrm{CH}_{4}$ after the Pinatubo eruption are: (a) the surface cooling, with tropospheric water vapor decrease as a response, followed by a decrease in $\mathrm{OH}$ and a longer $\mathrm{CH}_{4}$ lifetime; (b) Changes in $\mathrm{OH}$ resulting from the perturbed tropospheric UV budget, due to additional aerosol scattering and stratospheric ozone changes; (c) Increase of sulfate aerosol surface area density (SAD) in the mid-upper troposphere, thus enhancing heterogeneous chemistry with a decrease of tropospheric $\mathrm{NO}_{\mathrm{x}}$ and $\mathrm{OH}$.

For major tropical eruptions such as El Chichón and Pinatubo, the initial $\mathrm{SO}_{2}$ plume (located in the lower stratosphere) undergoes rapid $\mathrm{OH}$ oxidation [16,17], thus increasing the amount of gas phase $\mathrm{H}_{2} \mathrm{SO}_{4}$, which can form new nanometer-sized particles via binary homogeneous nucleation of $\mathrm{H}_{2} \mathrm{SO}_{4}$ and $\mathrm{H}_{2} \mathrm{O}[18,19]$. The new and existing particles coagulate both among themselves and also with each other, which together with the condensation of $\mathrm{H}_{2} \mathrm{SO}_{4}$ vapor, can grow the particles up to accumulation-mode sizes [20]. An optically thick cloud of supercooled sulfate aerosols is finally produced [21-23], which is highly reflective in the visible and ultraviolet UV. This radiative effect is particularly important in the tropics, where the aerosols (depending on the quasi-biennial oscillation phase) may remain confined for several months after the eruption with relatively high values of optical thickness. A typical example of a tropical eruption with a rather pronounced particle confinement in the tropical lower stratosphere is the 1991 Pinatubo case [24].

Volcanic aerosols impact the stratosphere through several radiative, chemical and dynamical effects [25]. They produce additional diabatic heating rates via direct interaction with solar near-infrared and planetary far-infrared radiation and indirect ozone absorption of the aerosol diffused UV-visible solar radiation [26]; in this way they heat the lower stratosphere. They produce significant ozone losses [27] via enhanced heterogeneous chemistry on sulfuric acid aerosols [28] and perturbed photolysis rates [29]. In case of tropical eruptions, the temperature increase is associated with a mid-latitude westerly wind anomaly. The latter favors vertical propagation of tropospheric planetary waves and additional tropical upwelling [26], with further decrease of lower stratospheric ozone [30]. The chemical-radiative-dynamical tropical ozone reduction in the enhanced aerosol layer offsets some of the warming.

A 2-3 K warming in the tropical lower stratosphere was measured in September-October 1991 after the Pinatubo eruption [31] and a 20\%-25\% ozone depletion in the 16-28 km layer over the tropics during October-November 1991 [32,33]. A model study by Telford et al. [34] calculated a global ozone column decrease by about 7 DU because of the Mt. Pinatubo eruption. The analysis of Hansen et al. [8] suggests that the largest change of the globally averaged net radiative top-of-atmosphere flux occurred during January $1992\left(-4.5 \mathrm{~W} / \mathrm{m}^{2}\right.$, for clear sky conditions and 0.15 optical thickness at $\left.\lambda=0.55 \mu \mathrm{m}\right)$ and decreasing afterwards with an $e$-folding time of approximately 12 months. Climate effects from the eruptions [35] reflect the overall net effects from all of these mechanisms, so that it is important to 
use models that include the processes that may underpin these effects, namely global variations in particle size distribution, radiative-chemical interactions and composition-dynamics interactions.

Upper stratospheric dynamical anomalies related to major volcanic eruptions have also been detected and highlighted. A study of Dunkerton and Delisi [36] on the stratospheric dynamical perturbations during 1982/83 (after the El Chichón eruption) shows how anomalies of temperature and zonal winds in the upper stratosphere could be explained as a consequence of the adiabatic cooling taking place in the tropical stratosphere due to the increased upwelling. A decrease of temperature was found at an altitude of about $40 \mathrm{~km}$, although a slightly positive diabatic anomaly was present there. Changes in diabatic heating rates due to absorbing volcanic aerosols, which warm the tropical lower stratosphere, perturb stratospheric dynamics and interplay with changes in extra-tropical planetary wave activity in the lower stratosphere. The increase in upwelling motion produced in the tropical stratosphere was found to be of the order of $10 \%-20 \%$ at approximately $30 \mathrm{hPa}$ [26].

Several modelling studies have been conducted to investigate the effects of volcanic aerosols on climate $[8,37,38]$ and on the stratospheric circulation $[29,30]$, assessing the effects from the interaction between aerosol and stratospheric dynamics on the volcanic cloud dispersal [39-41]. Examples of more recent modelling re-analyses of the Pinatubo perturbation are also available in literature, with focus on aerosol microphysics [42], aerosol dispersion [43] and ozone perturbations [34,44].

As discussed so far, the planetary scale transport of stratospheric species and the dispersal of volcanic aerosol clouds may be significantly affected by the radiative perturbations induced by the volcanic aerosols themselves. The phase of the quasi-biennial oscillation $(\mathrm{QBO})$ of equatorial mean zonal winds, however, is even more important for stratospheric trace species transport, including volcanic aerosols transport. Trepte and Hitchman [24] have studied the tropical stratospheric circulation using satellite aerosol data and have clearly shown the differences between dynamical regimes during dominant easterly or westerly shear of the QBO. The streamlines of the QBO circulation show that upwelling motion is enhanced everywhere in the tropical stratosphere (from the tropopause up to $30 \mathrm{~km}$ altitude) during years with dominant easterly shear. On the other hand, during years with dominant westerly shear, descent relative to the mean stratospheric circulation occurs over the equator and more aerosols can be transported down to altitudes within a few kilometers above the tropopause, where poleward isentropic transport is relatively fast. The main conclusion of Trepte and Hitchman [24] is that when the QBO easterly shear is present (as in the months following the Pinatubo eruption), aerosols are lofted higher over the equator with less meridional transport towards the poles compared to westerly QBO phase. The additional upwelling due to the Pinatubo aerosol radiative heating has therefore a feedback on the dynamics of the middle atmosphere similar to that of the QBO easterly shear and may additionally help to confine the particles in the tropical reservoir and to increase their lifetime.

An easterly QBO phase causes enhanced aerosol loading in the tropical stratosphere, but the warming of this enhanced aerosol may also modify the natural evolution of the QBO itself. This could be the case for a sustained injection of $\mathrm{SO}_{2}$ such as suggested for geoengineering experiments. In their study, Aquila et al. [45] found that such an injection dramatically alters the QBO, prolonging the phase of easterly shear with respect to the background atmosphere without geoengineering sulfur injection. In the case of maximum perturbation, the lower tropical stratosphere could even result to be locked into a permanent westerly $\mathrm{QBO}$ phase.

The purpose of the present study is to study the main features of the dispersal of stratospheric sulfate aerosol clouds following the most important tropical eruptions during the second half of the 20th century. We analyze the aerosol tropical confinement, lifetime and effective radius (as a proxy of the size distribution) and compare metrics of the stratospheric circulation changes for historical eruptions with differences in time of the year, atmospheric chemical composition, and $\mathrm{SO}_{2}$ injection, though mostly in the QBO phase (Agung and El Chichón in the westerly phase, Ruiz and Pinatubo in the easterly phase). 


\section{Experimental Section}

A short description of the composition-climate coupled model used in this study and its basic setups for the specific numerical experiments are presented in the following subsections. For more details on the model features we refer to Pitari et al. [46].

\subsection{University of L'Aquila-Composition-Climate Coupled Model (ULAQ-CCM)}

The University of L'Aquila model is a global scale composition-climate coupled model (ULAQ-CCM), including on-line aerosol-chemistry-climate interactions. It uses 126 log-pressure vertical levels extending from the surface to the mesosphere $(0.04 \mathrm{hPa})$, with a T21 horizontal resolution $\left(5^{\circ} \times 6^{\circ}\right.$ lat $\times$ lon). The ULAQ-CCM has been described in Pitari et al. [47] and also in Eyring et al. [48] and for the SPARC (i.e., Stratospheric Processes and their Role in Climate) climate-chemistry model validation (CCMVal) campaign. The most recent version of the ULAQ-CCM has been documented in Pitari et al. [46], with some important updates in regards to the SPARC-CCMVal exercise. The most important range is from the increase of vertical/horizontal resolution, to the use of JPL-2011 photolysis cross-sections [49], spherical geometry/refraction for twilight conditions, inclusion of solar cycle for top-of-atmosphere radiation fluxes and use of a two-stream delta-Eddington radiative transfer code evaluated in SPARC-Photocomp-2011 [50] and in AeroCom-2011 [51]. The ULAQ-CCM also includes an external forcing code for the $\mathrm{QBO}$, using a time series of monthly mean-observed equatorial zonal winds from 1960 to 2010 [52].

The chemistry module calculates the chemical evolution of long-lived and surface-flux species $\left(\mathrm{CH}_{4}, \mathrm{~N}_{2} \mathrm{O}, \mathrm{CFCs}, \mathrm{HCFCs}, \mathrm{CO}, \mathrm{NO}_{x}, \mathrm{NMVOC}\right.$ (i.e., non-methane volatile organic compounds)) and with medium- and short-lived species grouped in the families $\mathrm{O}_{\mathrm{x}}, \mathrm{NO}_{\mathrm{y}}, \mathrm{HO}_{\mathrm{x}}, \mathrm{CHO}_{\mathrm{x}}, \mathrm{Cl}_{\mathrm{y}}, \mathrm{Br}_{\mathrm{y}}, \mathrm{SO}_{\mathrm{x}}$, and aerosols. In total, there are 40 transported species, 26 species at photochemical equilibrium, and 57 size categories for the aerosols. The photochemistry module is organized with 140 gas-phase reactions, 45 photolysis reactions and 30 heterogeneous reactions on the surface of sulfate aerosols, nitric acid trihydrate and ice particles or water droplets.

The model includes the major components of stratospheric and tropospheric aerosols (sulfate, nitrate, organic and black carbon, soil dust, sea salt, PSCs). The ULAQ-CCM has on-line an aerosol module including $\mathrm{SO}_{\mathrm{x}}$ chemistry, gas-particle conversion (starting from $\mathrm{SO}_{2}$ oxidation by $\mathrm{OH}$ ) and microphysical processes for aerosol growth (homogeneous/heterogeneous nucleation, coagulation, condensation/evaporation). The aerosol particles formed in this way perturb the wavelength-dependent extinction, absorption and asymmetry parameter at all stratospheric vertical layers of the model, producing large perturbations in up/down diffuse radiation and absorption of solar near-infrared and planetary radiation, with consequent perturbations of $\mathrm{O}_{2}$ and $\mathrm{O}_{3}$ photolysis, $\mathrm{O}_{3}$ heating rates, aerosol heating rates in the solar and planetary infrared ranges [46].

The updated radiative transfer module operating on-line in the ULAQ-CCM, is a two-stream delta-Eddington approximation model for the calculation of photolysis rates in the ultra-violet (UV) to visible (VIS) wavelengths and for solar heating rates and radiative forcing in UV-VIS and solar near-infrared (NIR) bands [53]. In addition, a companion broadband, k-distribution longwave radiative module is used to compute radiative transfer and heating rates in the planetary infrared spectrum [54].

\subsection{Numerical Experiment Setup}

The model has been run for a total of 20 time-dependent simulations from 1960 to 2000. Of these numerical experiments, 10 will be from now on referred to as "reference" simulations (REF): they do not include the volcanic aerosols, except in the heterogeneous chemistry code, through use of externally specified time-dependent fields of SAD [55]. In this way, we may isolate the radiative impact of the volcanic aerosols, keeping heterogeneous chemistry unchanged. The other 10 experiments will be referred to as "volcanic perturbed" simulations (VE) with inclusions of the volcanic aerosols both in heterogeneous chemistry and in the radiative transfer code. Table 1 shows a summary of the major 
explosive eruptions from 1960 to 2000 included in the present study; the four tropical cases will be analyzed in detail.

Table 1. Major volcanic eruptions considered in the present study, with the adopted amounts of the injected $\mathrm{SO}_{2}$ and indication of the $\mathrm{QBO}$ E/W shear at the eruption time and following months.

\begin{tabular}{cccc}
\hline Eruption & Time & Tg-SO $_{2}$ & QBO E/W Shear \\
\hline Agung $(8 \mathrm{~S}, 11 \mathrm{E})$ & 16 May 1963 & 12 & $\mathrm{~W}$ \\
St. Helens $(46 \mathrm{~N}, 122 \mathrm{~W})$ & 18 May 1980 & 2.1 & $\mathrm{~W}$ \\
El Chichón $(17 \mathrm{~N}, 93 \mathrm{~W})$ & 4 April 1982 & 7 & $\mathrm{~W}$ \\
Nevado del Ruiz (5N,75W) & 13 November 1985 & 1.2 & $\mathrm{E}$ \\
Pinatubo (15N,120E) & 16 June 1991 & 20 & $\mathrm{E}$ \\
\hline
\end{tabular}

Ten different January 1st fields for the meteorological and tracer mixing ratios were taken from different years in the last 10 of a 20-year control time slice integration at perpetual 1960 conditions. These fields were then used to provide initial conditions for each of the ensemble members in the transient 1960-2000 REF and VE experiments. Monthly varying boundary conditions are used for sea surface temperatures and aerosol SAD. Top-of-atmosphere solar fluxes are also prescribed as monthly varying spectrally resolved solar irradiance data from the NRLSSI model. Details on the external data sources for sea surface temperatures, aerosol SAD and top-of-atmosphere solar fluxes are given in Eyring et al. [55].

Performing an ensemble of simulations allows to significantly increase the robustness of the calculated VE-REF anomalies for the main quantities involved in this study. As an example, the 20-30 hPa anomaly of the residual vertical velocity in the second half of 1991 (i.e., the Pinatubo case) is calculated to be $0.050 \pm 0.015 \mathrm{~mm} / \mathrm{s}$, with the uncertainty being the standard deviation from the ensemble of simulations. Another important example is the mid-stratospheric westerly wind anomaly in the second half of 1991, calculated in the range of $7-10 \mathrm{~m} / \mathrm{s}$ at $10 \mathrm{hPa}$ and $45^{\circ}$ latitude (see Section 3.1 for in-depth discussion). The interannual variability of mean zonal wind anomalies relative to a reference decade (1970-1979) is calculated to be $2.7 \mathrm{~m} / \mathrm{s}$ at the same location (i.e., $10 \mathrm{hPa}$ and $45^{\circ}$ latitude), measured by the standard deviation from the ensemble of all REF simulations.

\section{Results and Discussion}

Figure 1 shows the calculated time series of the stratospheric aerosol optical depth (AOD) at $\lambda=0.55 \mu \mathrm{m}$, compared with reference values taken from Sato et al. [56] and McCormick and Thomason [57] and available at NASA/GISS (http:/ / data.giss.nasa.gov/modelforce/strataer). The three largest eruptions (Agung 1963, El Chichón 1982, Pinatubo 1991) produce maximum stratospheric aerosol optical depth (AOD) ranging between 0.06 and 0.10 in the ULAQ-CCM, which are somewhat underestimated with respect to the NASA/GISS values. Note that the eruptions of Fernandina (1968) and Tolbachik (1975) have not been included in the model simulation. The calculated AOD is obtained by vertically integrating the aerosol extinction. This is in turn obtained from the aerosol size distribution calculated in the ULAQ-CCM aerosol microphysics module, with final conversion of the calculated particle concentration into aerosol extinction by means of a Mie scattering program [54].

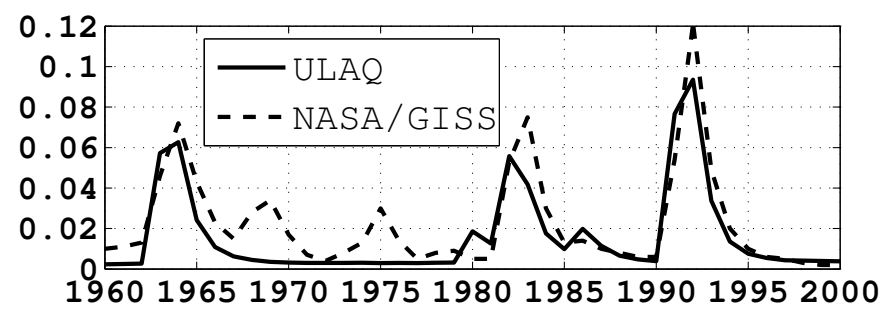

Figure 1. ULAQ-CCM-calculated time series of the global annual mean stratospheric aerosol optical depth at $\lambda=0.55 \mu \mathrm{m}$ (solid line), as an average from the VE simulations. As a comparison, the NASA/ GISS values are superimposed (http:/ / data.giss.nasa.gov/modelforce/strataer; dashed line) [56,57]. 
Figure 2 shows the observed equatorial zonal wind shear $(28 \mathrm{~km}-20 \mathrm{~km})$ with indication of the major volcanic eruptions considered in this study (see Table 1). The QBO is treated in the ULAQ-CCM using a nudging approach [52], with external data taken from merged observations of zonal winds at Canton Island, Gan and Singapore. The QBO phase is a critical parameter affecting the lower stratospheric tropical upwelling and horizontal mixing. In turn, a more pronounced tropical confinement increases the stratospheric lifetime of the volcanic aerosols, by slowing down the meridional transport outside the tropics. Their downward cross-tropopause transport, in fact, is produced by the extratropical lower branch of the Brewer-Dobson circulation and by the gravitational settling of accumulation and coarse mode aerosols.

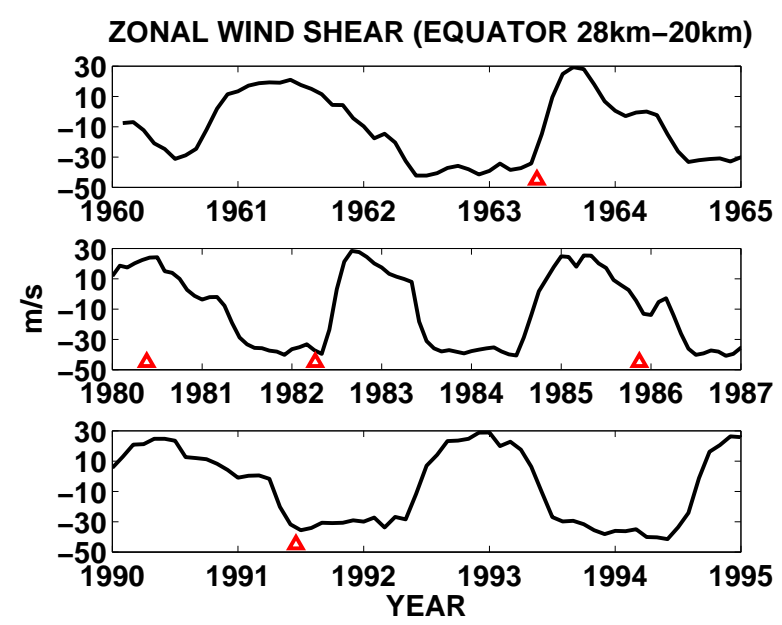

Figure 2. Time series of the observed equatorial zonal wind shear $(28 \mathrm{~km}-20 \mathrm{~km})$ with indication of the major volcanic eruptions considered in this study (red arrows).

\subsection{Lower Stratospheric Dynamical Anomalies}

Figure 3 shows the model-calculated time series of $50 \mathrm{hPa}$ annually averaged global mean temperature anomalies relative to the 1980-1989 decadal average, compared to ERA-40 (after 1980) and radiosonde data. The model prediction including the volcanic aerosol radiative interactions (VE) is close to the observed temperature increases during 1963/64,1982/83, 1991/92, contrary to the REF case. The observed globally averaged temperature increase of 1 or $1.5 \mathrm{~K}$ following Agung, El Chichón and Pinatubo eruptions is only present in the VE model simulation. A 2-3 K temperature increase was indeed observed during fall months of 1991 in the tropical lower stratosphere [31]. The VE case, in addition, gives a 1980-2000 temperature trend ( $-0.55 \mathrm{~K} /$ decade) closer to the observed ERA-40 trend $(-0.77 \mathrm{~K} /$ decade), with respect to the REF case $(-0.31 \mathrm{~K} /$ decade). The $50 \mathrm{hPa}$ decadal temperature trend is mainly driven by chemically/dynamically forced $\mathrm{O}_{3}$ decrease in the lower stratosphere and in part also by the increasing amount of well-mixed greenhouse gas and by the aerosol changes [55].

Figure 4 summarizes the radiative-dynamical anomalies after the Pinatubo eruption (Sept-Oct-Nov 1991), as calculated in the ULAQ-CCM (VE-REF). The heating rate anomaly is shown in the top two panels: the solar component (Figure 4a) is due to direct aerosol absorption in the NIR wavelengths and $\mathrm{O}_{3}$ absorption of the upward diffused radiation in the UV-VIS wavelengths. It is displaced somewhat above the longwave component, whose maximum is located closer to the temperature minimum in the region above the tropical tropopause layer (TTL). The latter component ("instantaneous" value with fixed REF temperatures) is summed up with the solar one in Figure 4b, to show the total aerosol diabatic perturbation. The maximum heating rate change VE-REF is calculated to be approximately $0.3 \mathrm{~K} /$ day, in the $20-25 \mathrm{~km}$ altitude layer between $15^{\circ} \mathrm{S}-15^{\circ} \mathrm{N}$ latitude. While the tropical stratosphere is warmed by the volcanically enhanced stratospheric aerosol, the tropical upper troposphere cools as a result of increased aerosol scattering of incoming solar radiation. The negative south polar anomaly of the diabatic heating rates is due to additional $\mathrm{O}_{3}$ depletion on enhanced 
surface area density of PSCs, produced by dynamical cooling [46] (decreased horizontal eddy heat fluxes at mid-high latitudes). An average 3-4 K temperature increase (Figure $4 \mathrm{c}$ ) is predicted during the fall months of 1991 in the 30-50 hPa layer over the tropics. Observations collected in Labitzke and McCormick [31] have shown a 30\% smaller warming, with respect to June-July 1991 mean values. The temperature anomaly in Figure $4 \mathrm{c}$ induces a significant increase of westerly winds from the thermal wind equation, with peaks at mid-latitudes in the mid-stratosphere (Figure 4d).
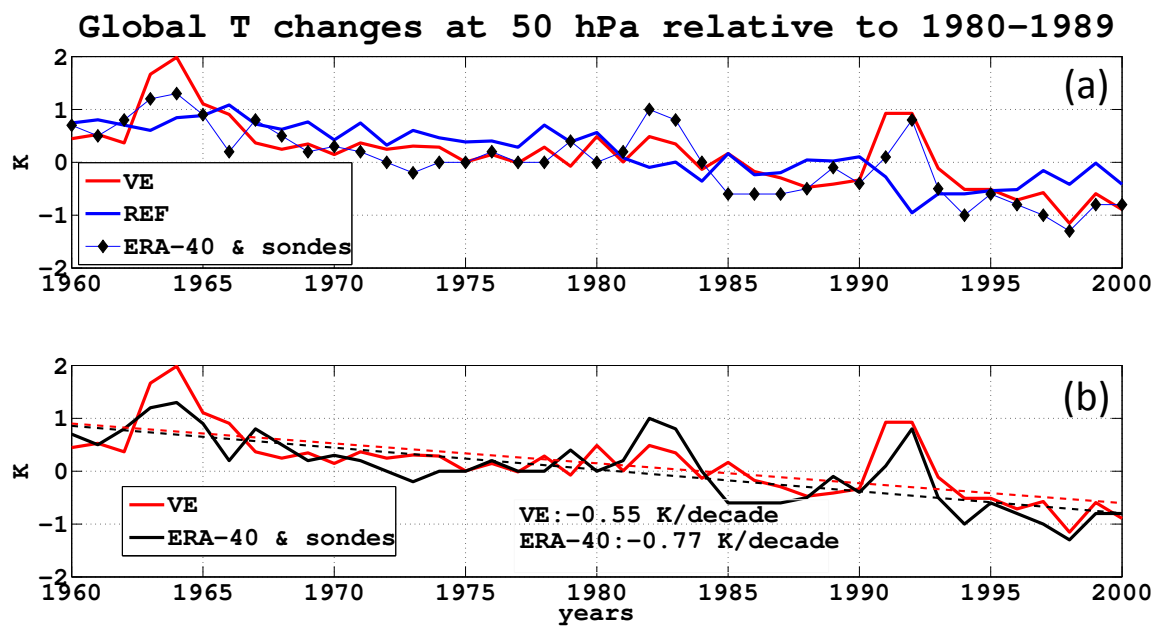

Figure 3. Time series of $50 \mathrm{hPa}$ annually averaged global mean temperature anomalies relative to the 1980-1989 decadal average (VE, REF, OBS) (a). Linear trends of the temperature anomalies are superimposed to (VE, OBS) time series in panel (b) $(-0.55 \mathrm{~K} /$ decade for VE and $-0.77 \mathrm{~K} /$ decade for ERA-40 reanalysis, for 1980-2000 trends). Observations are from Uppala et al. [58]; Free et al. [59].

(a) SW HEATING RATE CHANGES [K/day]

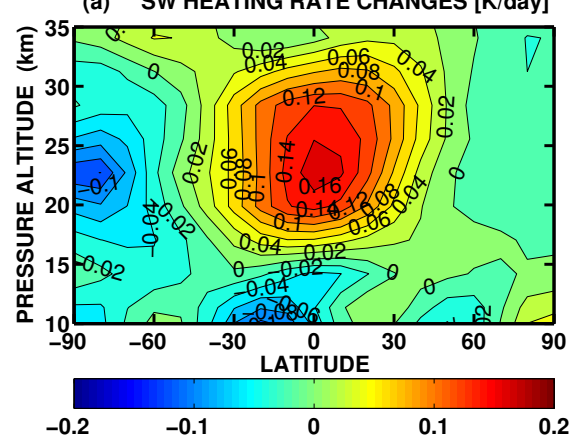

(c) TEMPERATURE CHANGES [K]

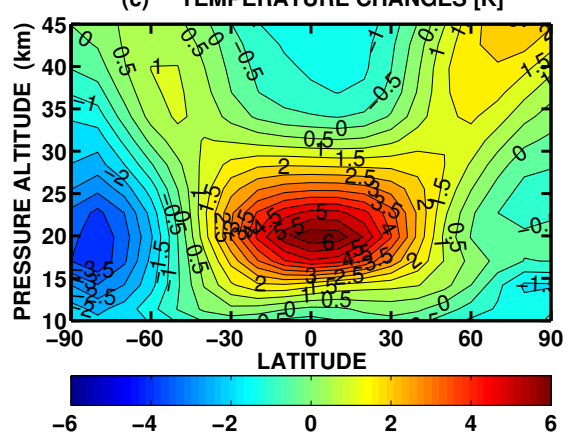

(b) SW+IR Q CHANGES [K/day] (REF TEMP)

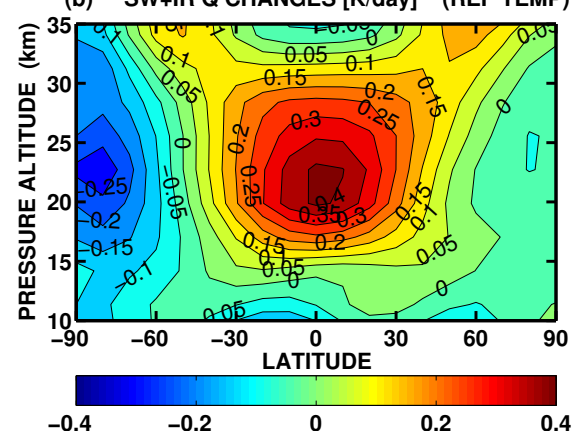

(d) MEAN ZONAL WIND CHANGES [m/s]

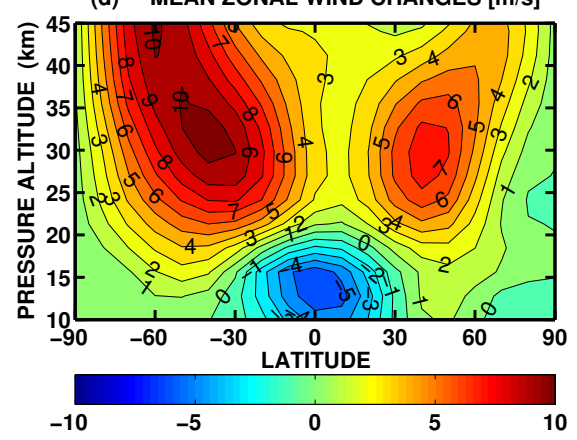

Figure 4. ULAQ-CCM-calculated mean zonal anomalies due to the Pinatubo aerosols (VE-REF), during September-October-November 1991: (a) solar heating rates (K/day); (b) total heating rates, i.e., solar + longwave ("instantaneous" value with fixed REF temperatures) (K/day); (c) temperatures (K); (d) zonal winds (m/s). 
These zonal wind positive changes favor the propagation of planetary waves into the stratosphere with enhanced tropical upwelling. This is summarized in Figure 5, where the calculated amplitude anomaly of planetary waves 1-2 is shown in the left panel, along with the associated perturbation of the residual vertical velocity in the right panel. The latter is shown for the second half of 1991: it accounts for approximately $10 \%-20 \%$ of the baseline REF upwelling in the $30-50 \mathrm{hPa}$ layer over the tropics, with an increased downward component at mid-latitudes. Aquila et al. [44] have shown how the coupling of enhanced heterogeneous chemical reactions on Pinatubo volcanic aerosols (causing $\mathrm{O}_{3}$ depletion) with this strengthening of the Brewer-Dobson circulation may explain the observed unexpected column ozone increase in the Southern Hemisphere $(\mathrm{SH})$ mid-latitudes in the months following the eruption. This modification of the stratospheric transport, together with the season of the year and the direction of the Brewer-Dobson circulation, moved mid-stratospheric tropical ozone-rich air masses to the $\mathrm{SH}$ mid-latitudes, causing the unexpected increase of column ozone there. In the Northern Hemisphere (NH) mid-latitudes, on the other hand, the chemical depletion dominated the ozone perturbation in the six months after the eruption. Our results in Figure 5, which include volcanic perturbations to the SAD in the REF and VE simulations, also show a larger positive/negative displacement of the residual vertical velocity anomaly in Northern/Southern Hemisphere, respectively.

(a) WAVE \#1\&2 AMPLITUDE CHANGES [gpm]



(b) W* CHANGES [mm/s] Jul-Dec 1991

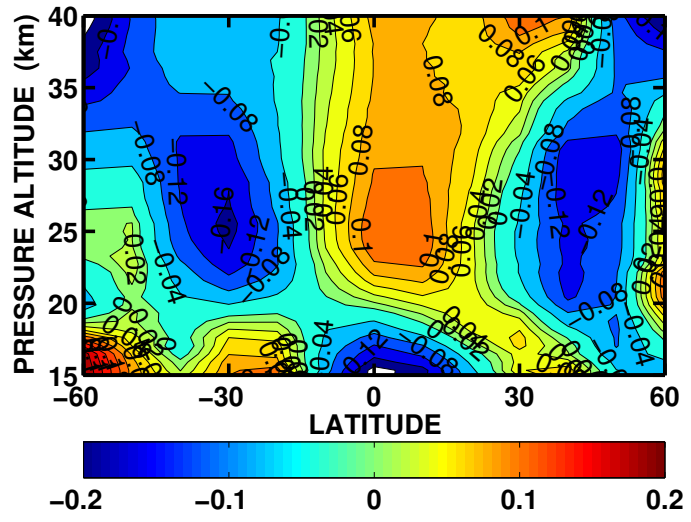

Figure 5. ULAQ-CCM-calculated mean zonal anomalies due to the Pinatubo aerosols (VE-REF):

(a) amplitude of geopotential wavenumber 1 and 2 (m), during September-October-November 1991;

(b) residual mean vertical velocity, averaged from July to December 1991.

\subsection{Equatorial Winds Quasi-Biennial Oscillation (QBO) and Aerosol Transport}

Figure 6 shows the different latitude/altitude patterns of aerosol extinction for the considered tropical eruptions, correlated with the equatorial wind QBO phase. Using satellite aerosol data, Trepte and Hitchman [24] have shown the differences between dynamical regimes during dominant $\mathrm{E}$ or W shear of the QBO of the equatorial stratosphere. During years with dominant $\mathrm{E}$ shear, the streamlines of the circulation anomaly caused by the QBO show definite upwelling motion extended everywhere in the tropical stratosphere. During years with dominant $\mathrm{W}$ shear, descent relative to the mean stratospheric circulation occurs over the equator and lower stratospheric air masses can be transported within a few kilometers above the tropopause, where poleward isentropic transport is relatively fast. Figure 6 shows the ULAQ model prediction of zonally averaged aerosol extinction at $\lambda=0.55 \mu \mathrm{m}$, four months after each tropical eruption. Only in 1986 and 1991 (QBO E shear) is the aerosol extinction highly confined around the equator with large values well above $25 \mathrm{~km}$ altitude. During years with dominant QBO E shear, as in the months following the Ruiz and Pinatubo eruptions (Figure 6a,b), aerosols are lofted over the equator with less poleward transport. This better tropical confinement of the volcanic aerosols with respect to years with dominant QBO W shear, as in the months following the Agung and El Chichón eruptions (Figure $6 c, d$ ), produces a larger latitudinal gradient of the perturbation heating rates, with stronger impact on the tropical upwelling. Some 
differences in plume evolution of these particular eruptions may also arise simply because of their different latitude, so that some of them are closer to the edge of the tropical pipe than others (e.g., El Chichón).
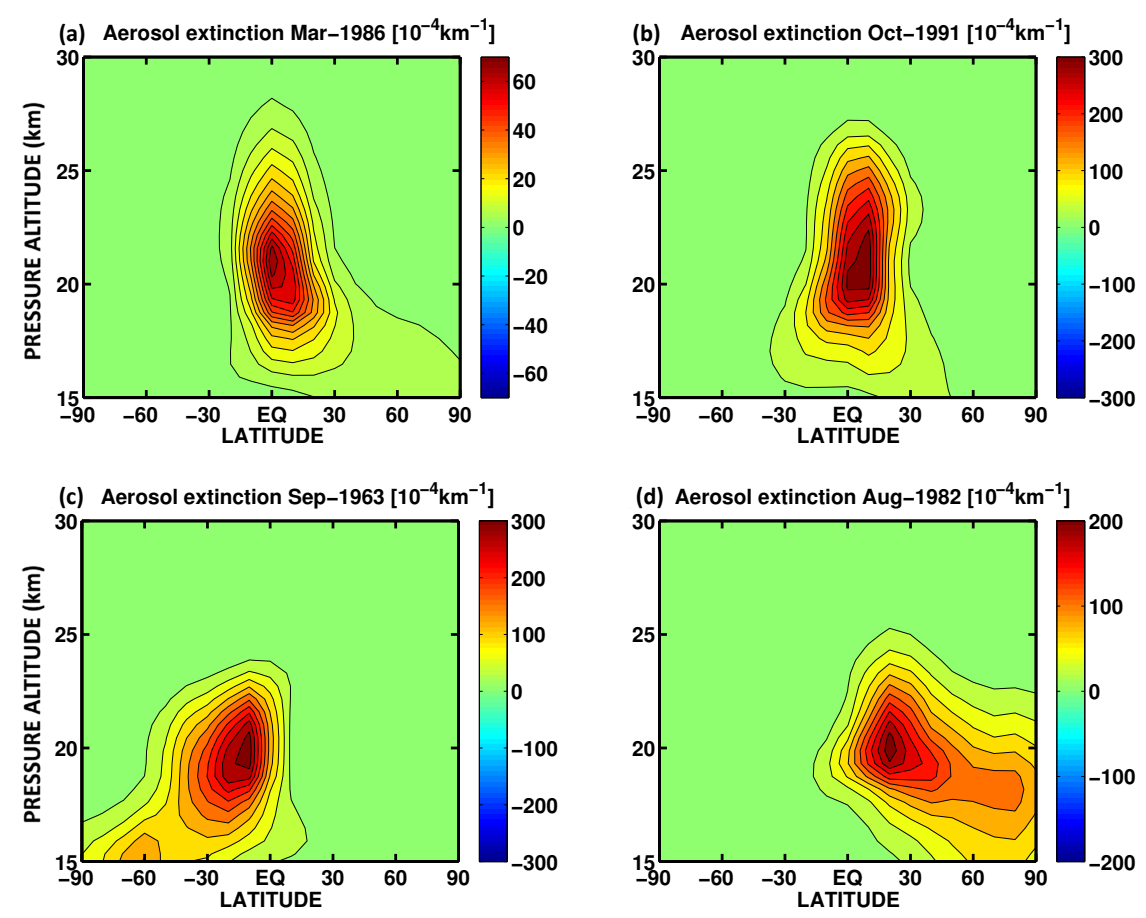

Figure 6. Top panels $(\mathbf{a}, \mathbf{b})$ show the ULAQ model prediction of zonally averaged aerosol extinction at $\lambda=0.55 \mu \mathrm{m}$ during the month of March 1986 (a) and October 1991 (b), following the major eruptions of Nevado del Ruiz (a) and Pinatubo (b) (E wind shear). Bottom panels (c,d) as in (a,b) but for September 1963 (c) and August 1982 (d), following the major eruptions of Agung (c) and El Chichón (d) (W wind shear). Only in March 1986 and October 1991 (E wind shear) is the aerosol extinction strongly confined around the equator with high values well above $24 \mathrm{~km}$ altitude.

Vertical profiles of the tropical aerosol extinction four months after each eruption are shown in Figure 7a and compared with satellite and lidar observations for the Ruiz and Pinatubo volcanic perturbations. The reference volcanically clean vertical profile of the background aerosol extinction at the Equator is also shown and compared with SAGE-II data. The clear difference in aerosol extinction above $25 \mathrm{~km}$ can be seen between Agung and El Chichón on one side (QBO W shear), and Ruiz and Pinatubo on the other side (QBO E shear). The zonal-mean latitudinal sections of the aerosol extinction at $20.5 \mathrm{~km}$ during the same months of Figure $7 \mathrm{a}$ are presented in Figure $7 \mathrm{~b}$, where the more pronounced tropical confinement of the aerosol clouds after Ruiz and Pinatubo eruptions is also clear. A comparison of the model-calculated heating-rate changes (VE-REF) is presented in Figure 7c, where the zonal-mean latitudinal sections of the instantaneous heating-rate changes are shown (i.e., fixed temperature and ozone fields). The latitudinal gradient of the aerosol heating rates is one of the primary drivers for the stratospheric dynamical anomalies. The enhanced aerosol tropical confinement during QBO E shear episodes produces much higher heating rate gradients between mid-latitudes and the tropics, with respect to the QBO W shear episodes. We calculate $0.28 \mathrm{~K} /$ day and $0.023 \mathrm{~K} /$ day for Pinatubo and Ruiz, versus $0.0045 \mathrm{~K} /$ day and $0.075 \mathrm{~K} /$ day for El Chichón and Agung, all calculated as the difference between an average over the latitude region $15^{\circ} \mathrm{S}-15^{\circ} \mathrm{N}$ and an average of the heating-rate changes at $45^{\circ} \mathrm{S}$ and $45^{\circ} \mathrm{N}$. Note that the ratio of the heating-rate changes for Pinatubo and Ruiz is consistent with the different magnitude of the initial $\mathrm{SO}_{2}$ injection (20 and $1.2 \mathrm{Tg}-\mathrm{SO}_{2}$, respectively). On the other hand, the ratios of the heating-rate changes for Pinatubo and Agung (3.7) or Pinatubo and El Chichón (62) are much larger than the corresponding ratios of the initial $\mathrm{SO}_{2}$ injections (1.67 and 2.86, respectively). 
(a) Extinction profiles $(\lambda=0.55 \mu \mathrm{m})$

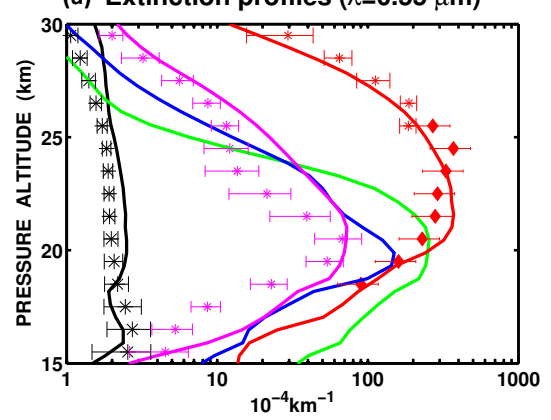

(b) Aerosol extinction $(z=20.5 \mathrm{~km})$

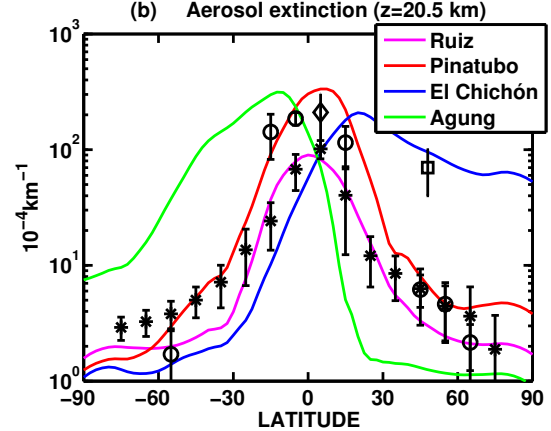

(c) SW+IR heating rates at $70 \mathrm{hPa}$

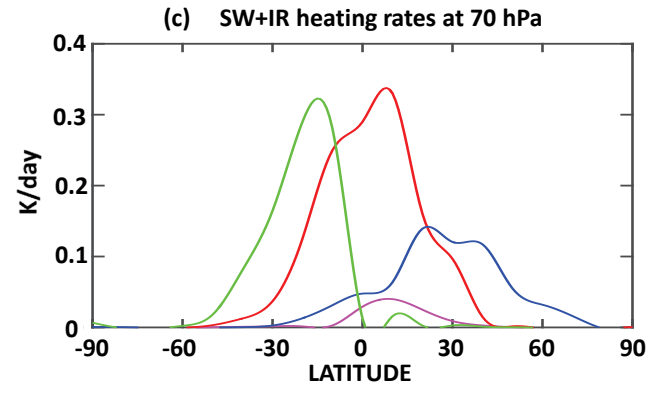

Figure 7. Top left panel (a) model-calculated vertical profiles of the aerosol extinction at $5^{\circ} \mathrm{N}$ for Pinatubo during October 1991 (red) and $5^{\circ} \mathrm{S}$ for Ruiz during March 1986 (magenta): cases with E shear of the equatorial winds; at $10^{\circ} \mathrm{N}$ for El Chichón during August 1982 (blue) and at $5^{\circ} \mathrm{S}$ for Agung during September 1963 (green): cases with W shear of the equatorial winds. A volcanically clean extinction profile at $5^{\circ} \mathrm{N}$ is shown in black, averaged over 1999-2000. SAGE-II observations are shown with asterisks and uncertainty bars: black for 1999/2000, magenta for March 1986 (Ruiz), red for October 1991 (Pinatubo). Pinatubo observations are from SAGE-II observations only above $25 \mathrm{~km}$ altitude (since the instrument was saturated below this altitude); lidar observations (red diamonds) are used below $25 \mathrm{~km}$ [32]. The clear difference in aerosol extinction above approximately $24 \mathrm{~km}$ can be seen between Agung and El Chichón on one side (QBO W shear) and Pinatubo and Nevado del Ruiz on the other side (QBO E shear). Top right panel (b) zonal-mean latitudinal section of the model-calculated aerosol extinction at $20.5 \mathrm{~km}$ altitude, compared with SAGE-II data: black asterisks for March 1986 (Ruiz), black circles for October 1991 (Pinatubo) (at $25.5 \mathrm{~km}$ in the tropics). The black diamond is derived from lidar measurements of Grant et al. [32] for October 1991 (Pinatubo) at $20.5 \mathrm{~km}$; the black square is from lidar measurements of Jäger and Hofmann [60] for August 1982 (El Chichón). Bottom panel (c) zonal-mean latitudinal section of the model-calculated aerosol heating-rate changes VE-REF at $70 \mathrm{hPa}$ (K/day) for the aerosol distribution four months after each eruption, as in panels (a) and (b) (instantaneous SW + IR heating-rate changes, with fixed temperature and ozone fields).

The conclusions of Trepte and Hitchman [24] relative to the variant equatorial upwelling regime during W/E shear of the QBO were based on direct satellite observations of aerosol extinction (SAGE-II time series). In Figure 8, we compare the vertical profiles of the ULAQ-CCM-calculated residual mean vertical velocity $\left(\mathrm{w}^{*}\right)$ over the tropics $\left(15^{\circ} \mathrm{S}-15^{\circ} \mathrm{N}\right)$. To illustrate the contrasting circulation in the easterly and westerly QBO phase, we have paired up the westerly QBO eruptions with a corresponding easterly QBO eruption, with El Chichón and Pinatubo paired in panels $(\mathrm{a}, \mathrm{c})$ of Figure 8, and Agung and Ruiz paired up in panels $(b, d)$ of Figure 8. The $w^{*}$ anomalies shown in Figure $8 c, d$ are calculated by subtracting a reference velocity profile averaged from 1960 to 2000 (a linear trend of $0.006 \mathrm{~mm} \cdot \mathrm{s}^{-1} /$ decade is removed from the ULAQ-CCM time series of $\mathrm{w}^{*}$, mostly due to time-increasing well-mixed greenhouse gases). A significant descent relative to the mean stratospheric circulation is found above approximately $30 \mathrm{hPa}$, during years with dominant $\mathrm{W}$ shear, as indirectly obtained from satellite measurements of aerosol extinction. In addition, we find that the tropical $\mathrm{w}^{*}$ increase in the VE experiments relative to REF is much larger (and also extended in 
time) during 1991 and 1986, with respect to the years interested by Agung and El Chichón volcanic aerosol (1963 and 1982). This is an indirect consequence of the higher tropical confinement of the aerosols in 1991 and 1986, essentially due to the QBO E shear circulation following Pinatubo and Ruiz eruptions. This enhanced confinement helps in producing a diabatic heating perturbation with a significantly larger latitudinal gradient with respect to the volcanic episodes coincident with the QBO W shear (see Figure 7c). Aerosol microphysical effects could potentially be superimposed onto the tropical confinement of the particles, thus changing their size distribution and modifying scattering and absorption; this will be discussed later, in relation to the calculated radiative flux changes.
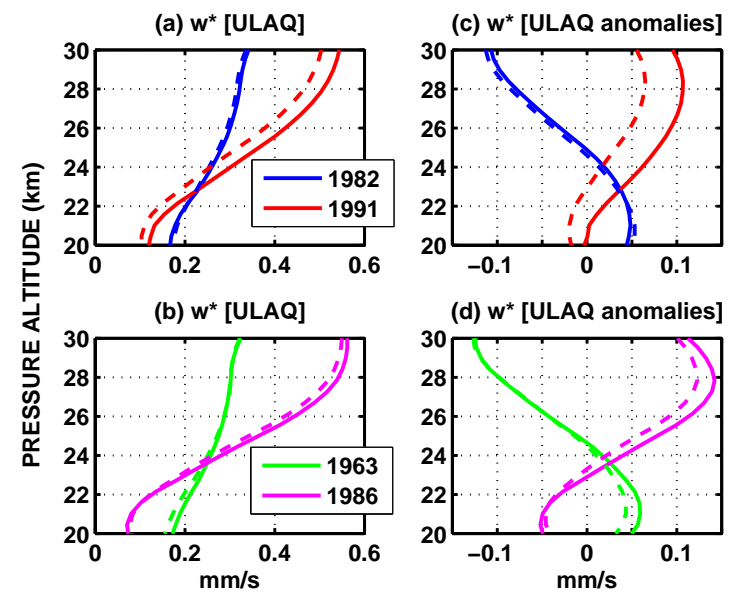

Figure 8. Left panels $(\mathrm{a}, \mathrm{b})$ ULAQ-CCM residual mean vertical velocity profiles $(\mathrm{mm} / \mathrm{s})$ from 20 to $30 \mathrm{~km}$ altitude, averaged between $15^{\circ} \mathrm{S}$ and $15^{\circ} \mathrm{N}$ latitude; panel (a) time average during 1982 (El Chichón, W shear, blue) and 1991 (Pinatubo, E shear, red); panel (b) time average during 1963 (Agung, W shear, green) and 1986 (Ruiz, E shear, magenta). Right panels (c,d) as in panels (a,b), but for the anomalies of the residual mean vertical velocity, calculated with respect to the 1960-2000 average. Solid/dashed curves are for VE and REF simulations, respectively.

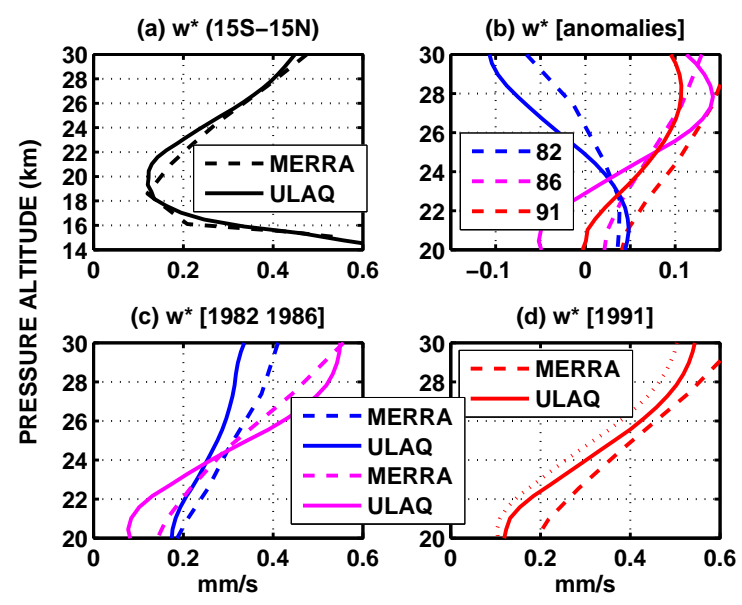

Figure 9. Panel (a) evaluation of the ULAQ-CCM lower stratospheric tropical upwelling (solid line, VE simulation) with MERRA reanalysis data (dashed line), in terms of the residual mean vertical velocity profile $(\mathrm{mm} / \mathrm{s})\left(15^{\circ} \mathrm{S}-15^{\circ} \mathrm{N}\right.$ latitudinal average). Velocity profiles are averaged from 1979 to 2000 for both ULAQ-CCM and MERRA. Panel (b) as in (a), but for the anomalies of the residual vertical velocity with respect to the long-term averages of panel (a), calculated during 1982 (El Chichón, W shear, blue), 1986 (Ruiz, E shear, magenta) and 1991 (Pinatubo, E shear, red). Panels (c,d) as in panel (a), but for years 1982 (El Chichón, W shear, blue) and 1986 (Ruiz, E shear, magenta) in (c); and for 1991 (Pinatubo, E shear, red) in (d). Solid/dashed curves are for ULAQ-CCM (VE simulations) and MERRA data, respectively. The dotted line in panel (d) shows the ULAQ-CCM 1991 results for the REF simulation. 
An additional support to the ULAQ-CCM findings comes by comparing the $\mathrm{w}^{*}$ vertical profiles (and anomalies) with those available from the Modern Era Retrospective-Analysis for Research and Applications (MERRA) reanalysis [61] (Figure 9) (a linear trend of $0.012 \mathrm{~mm} \mathrm{~s}^{-1} /$ decade is removed in this case from the MERRA time series of $\mathrm{w}^{*}$ ). The 22-year average (1979-2000) of the ULAQ-CCM results shown in Figure 9a is in good agreement with MERRA data averaged over the same years, except for some overestimation immediately above the TTL and some underestimation in the $20-22 \mathrm{~km}$ layer. The 1982 negative $\mathrm{w}^{*}$ anomaly above $30 \mathrm{hPa}$ shown in Figure 8 is also found in the MERRA reanalysis (Figure 9b), contrary to the 1986 and 1991 cases (E shear of the QBO). A direct comparison of 1982 and 1986 w* $^{*}$ profiles is presented in Figure 9c, whereas 1991 is in Figure 9d, all showing a satisfactory consistency. In the latter case, we also see that the VE simulation including the effects of aerosol heating compares better with the MERRA profile in respect to the REF results. Younger age of air is predicted in VE with respect to REF [62], for at least one year after the Pinatubo eruption, mainly as a consequence of the enhanced tropical upwelling [63].

\subsection{Aerosol Cloud Dispersal and e-folding Time}

Gas-particle conversion processes typically last for approximately 4-6 months from the explosive eruption and produce an optically thick cloud of supercooled sulfuric acid aerosols. At this point, the stratospheric global amount of aerosol mass reaches its maximum and then a continuous slow decrease of the global burden begins, due to particle loss from the stratosphere into the troposphere, where the aerosols are readily removed by wet scavenging. This stratosphere-troposphere exchange follows essentially two pathways: (a) large-scale transport following the downwelling branch of the Brewer-Dobson stratospheric circulation; and (b) gravitational settling of the particles. The effectiveness of these two processes determines the volcanic aerosol global lifetime, measured as the $e$-folding time of the initial cloud. Process (a) is strongly affected by the length of time the cloud remains in the tropical pipe, where the large-scale atmospheric dynamics is characterized by slow mean zonal upwelling and limited horizontal eddy mixing across the subtropical barriers. The stronger the tropical pipe isolation, the longer the aerosol export time towards mid-high latitudes where large-scale air descent is associated with the downwelling branch of the Brewer-Dobson circulation. In this case, the aerosols reside longer within the stratosphere, thus favoring a longer $e$-folding time of the volcanic cloud. As previously discussed in Figures 6-9 process (b) is largely governed by the QBO phase: a longer aerosol lifetime is expected during months with an $\mathrm{E}$ shear of the equatorial zonal winds. Process (b) is governed by the average size of the particles, which is in turn related to the magnitude of the initial amount of $\mathrm{SO}_{2}$ injected in the stratosphere. The larger the $\mathrm{SO}_{2}$ amount, the larger the effective radius (i.e., the surface-area-weighted particle size across the entire radius spectrum), the faster gravitational settling and the shorter the volcanic cloud $e$-folding time.

The cooperation of these two regulating processes of the stratospheric aerosol residence time (i.e., the dynamical and microphysical removal pathways) has a clear impact on the volcanic cloud dispersal, as shown in Figure 10. Starting from the time series of the volcanic $\mathrm{SO}_{4}$ global mass ratio relative to its maximum value (Figure 10a), we have then separated the time tendency during the first and second year after each eruption (Figure 10b,c, respectively). The $e$-folding time during the second year (referring to the decay in the sulfate global mass burden) is rather similar for all the tropical eruptions (10-12 months), since the coarser particles have already been lost by sedimentation and a significant amount of the aerosol has been transported outside the tropics. This estimate is consistent with SAGE-II observations of the Pinatubo aerosol cloud decay and results from other global models [64]. On the other hand, the $e$-folding time shows considerable variability during the first year, with the largest values for Ruiz and Pinatubo eruptions (E shear of the QBO), contrary to Agung and El Chichón (W shear of the QBO). The ULAQ-CCM-calculated values are approximately 31 and 15 months for Ruiz and Pinatubo, contrary to 10 and 8 months for Agung and El Chichón, respectively. The very long lifetime calculated in the Ruiz case is likely caused by the much smaller amount of the injected $\mathrm{SO}_{2}$ in this case, with a consequently much smaller effective radius of the 
aerosol size distribution spectrum. The $\mathrm{SO}_{2}$ time series during the first six months after each eruption is presented in Figure 10d. The $\mathrm{SO}_{2} e$-folding time is primarily governed by the regulating factors of the $\mathrm{OH}$ stratospheric abundance: (a) altitude-latitude position of the initial cloud; (b) eruption time of the year; (c) $\mathrm{SO}_{2}$ magnitude. Point (c) is probably the most important because the reaction $\mathrm{OH}+\mathrm{SO}_{2}$ not only represents the dominant sink of $\mathrm{SO}_{2}$ forming sulfate after multi-step gas-phase reactions, but also accelerates the $\mathrm{OH}$ conversion into $\mathrm{HO}_{2}$, which is normally driven by $\mathrm{NO}_{x}$ and $\mathrm{O}_{\mathrm{x}}$ in volcanically quiet conditions of the stratosphere. This is most likely to be the reason for the shorter $\mathrm{SO}_{2}$ lifetime in the Ruiz case (more abundant $\mathrm{OH}$ due to an inefficient sink by sulfur dioxide). The calculated $e$-folding time in the Pinatubo case (31 days) is rather close to the value derived from MLS satellite observations [17].
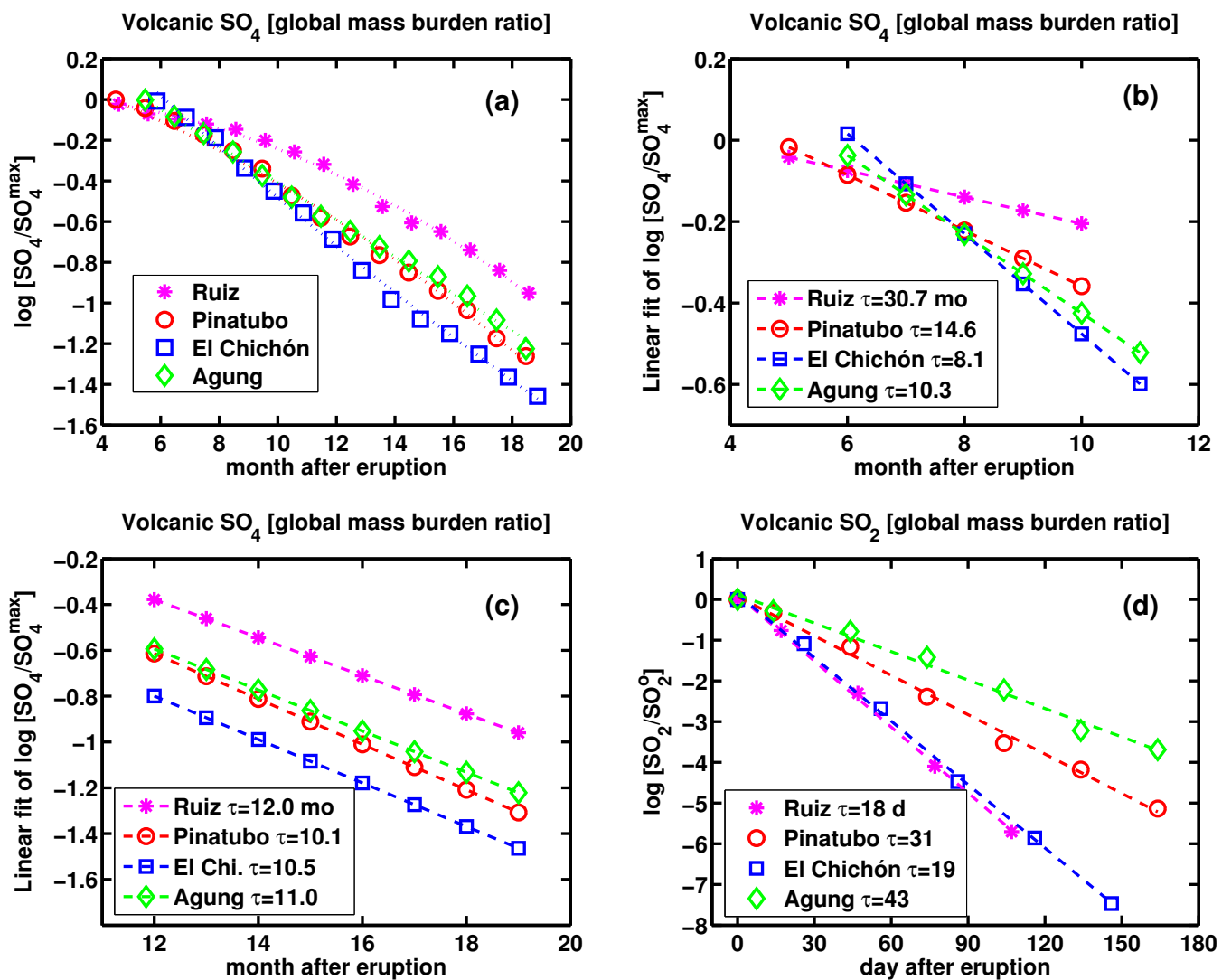

Figure 10. Panels (a-c): time series of volcanic $\mathrm{SO}_{4}$, as globally integrated mass burden ratio with respect to its maximum value, reached 5-6 months after each eruption (see legend for the line styles adopted for the tropical eruptions considered in this study). Panel (a) shows the ULAQ-CCM-calculated values up to approximately 19 months after each eruption; panels (b) and (c) show the values obtained from a linear fit in the time frame of post-eruption months 4-10 (or 5-11) in (b) and months 12-19 in (c). In the legends of panels $(\mathrm{b}-\mathrm{c})$ the calculated $e$-folding times of volcanic $\mathrm{SO}_{4}$ are presented. Panel (d) is similar to (b), but in this case the globally integrated $\mathrm{SO}_{2}$ mass burden ratio with respect to its initial value is shown, as from the ULAQ-CCM calculations. In the legend, the calculated $e$-folding time of volcanic $\mathrm{SO}_{2}$ is presented (referring to the decay in the sulfate global mass burden).

The microphysical processes (homogeneous nucleation, coagulation, gas condensation) produce a size distribution of the volcanic aerosols with two clear peaks, the first for the ultrafine Aitken mode, the second for the accumulation of optically active particles (Figure 11a). The latter results from the gas-particle interaction, with the mode radius moving to larger values proportionally to the amount of the injected $\mathrm{SO}_{2}$. The time evolution of the aerosol size distribution in the early stages after the eruption is summarized in Figure $11 \mathrm{~b}$ for the Pinatubo case. The accumulation mode moves 
with time towards larger radii, gaining mass from self-coagulation of molecular clusters formed via homogeneous nucleation and from condensation of $\mathrm{H}_{2} \mathrm{SO}_{4}$ gas formed via $\mathrm{SO}_{2}$ oxidation. The distinct peak at around $6 \mu \mathrm{m}$ in the coarse mode is due to direct stratospheric injection of large ash particles, which have been removed within a few weeks via gravitational settling. The peak is still apparent on July 15th, but is very weak and has shifted to smaller size. The aerosol mass distribution is presented in Figure 11c, showing the particle volume distribution: as expected, it mostly reflects the growth of the accumulation mode discussed in Figure 11a. The overall result of these processes can be summarized with the time series of the aerosol effective radius (Figure 11d), which again follows directly the evolution of the accumulation mode. For the Ruiz and Pinatubo cases an evaluation of the ULAQ model results is made using SAGE-II-retrieved values. The $\mathrm{r}_{\text {eff }}$ growth in the Pinatubo case represents the variations indicated by the values derived from SAGE-II extinction measurements [64], from the initial background value of $\sim 0.2 \mu \mathrm{m}$ up to $\sim 0.6 \mu \mathrm{m}$ after approximately 6 months from the eruption. The subsequent $\mathrm{r}_{\text {eff }}$ decline is mostly produced by the gravitational settling of the largest particles, arriving at $\sim 0.45 \mu \mathrm{m} 18$ months after the eruption. As already discussed in Figure 10, the aerosol size distribution in the Ruiz case produces much smaller particles, giving a significantly longer $e$-folding time $\left(\mathrm{r}_{\text {eff }} \sim 0.25 \mu \mathrm{m}\right)$.
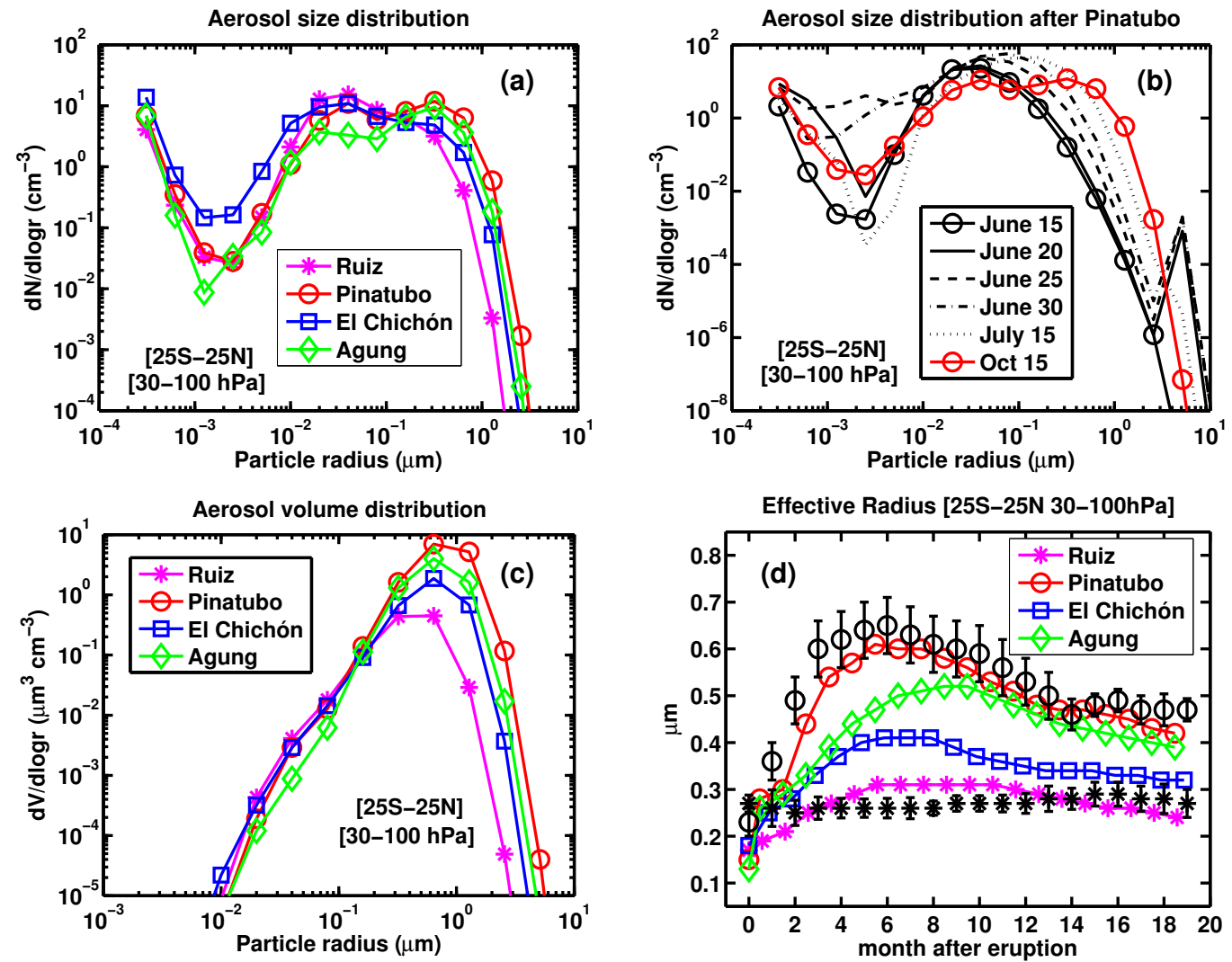

Figure 11. Panel (a) ULAQ-CCM-calculated aerosol size distribution $[\mathrm{dN} / \mathrm{dlogr}]\left(\mathrm{cm}^{-3}\right)$ averaged between $25^{\circ} \mathrm{S}-25^{\circ} \mathrm{N}$ latitude and $30-100 \mathrm{hPa}$, four months after each eruption (see legend for the line styles adopted for the tropical eruptions considered in this study). Panel (b) as in (a), but for the Pinatubo case as a function of time, from immediately before the eruption (June 15, 1991) to June 30 every 5 days and then 15 July and 15 October, i.e., four months after the eruption, as in panel (a). Panel (c) as in (a), but the volume distribution $[\mathrm{dV} / \mathrm{dlogr}]\left(\mu \mathrm{m}^{3} \cdot \mathrm{cm}^{-3}\right)$ is a proxy of the mass distribution. Panel (d) time series of the aerosol effective radius $(\mu \mathrm{m})$, calculated in the lower stratospheric tropical domain $\left(25^{\circ} \mathrm{S}-25^{\circ} \mathrm{N}\right.$ and $\left.30-100 \mathrm{hPa}\right)$; black symbols show SAGE-II-retrieved values [64], with open circles for Pinatubo (1991/92) and asterisks for Ruiz (1986/87). SAGE-II effective radius values for the first 12 months after the Pinatubo eruption are calculated by interpolating the missing data in the 20-25 km layer (due to instrument saturation). 


\subsection{Aerosol Radiative Flux Changes}

The volcanic AOD time series (VE-REF)-calculated in the model is presented in Figure 12a and is compared with satellite data for Ruiz and Pinatubo cases, using data from SAGE-II [65] and AVHRR [18] retrievals. Background values were removed from AVHRR observations [43] by subtracting the background values over the corresponding months preceding the Pinatubo eruption, following the method described in Long and Stowe [23]. The simulated peak value is in reasonable agreement with AVHRR, although slightly underestimated, and occurred earlier in time than in the SAGE II data. However, the AOD calculated from SAGE II observations is probably underestimated, due to saturation of the SAGE-II instrument [18].
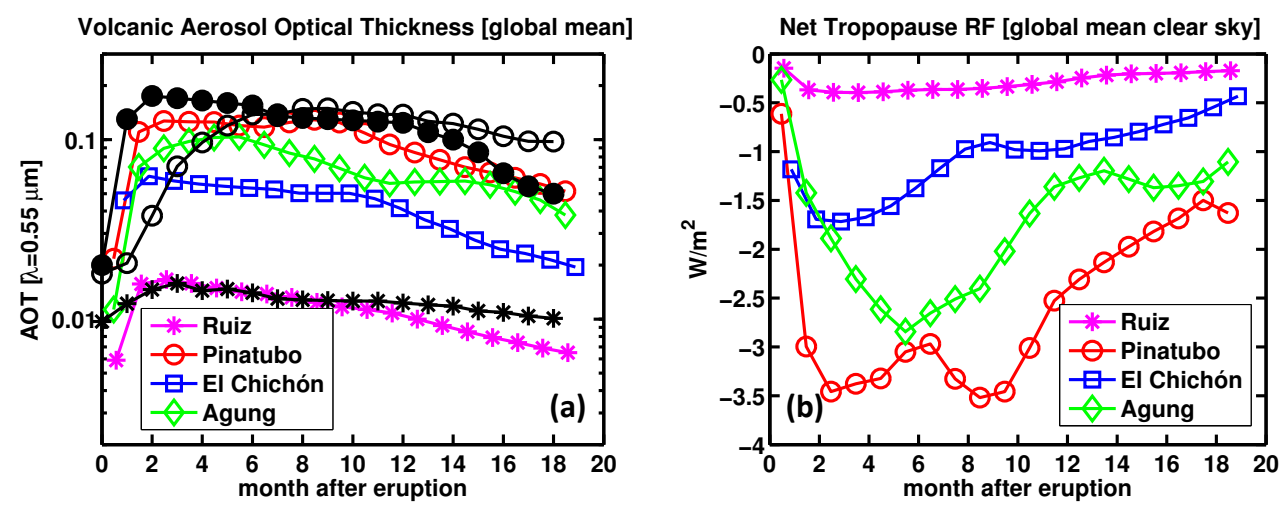

Figure 12. Panel (a) time series of the calculated global mean optical depth of volcanic aerosols (see legend). Black asterisks show SAGE-II values for the Ruiz eruption; black open and filled-up circles show post-Pinatubo values from SAGE-II [65] and AVHRR [23], respectively. Background values were removed from AVHRR observations (see text). Panel (b) time series of the calculated net tropopause $\mathrm{RF}$ due to the volcanic aerosols (global mean for clear sky conditions) $\left(\mathrm{W} / \mathrm{m}^{2}\right)$.

The calculated net radiative flux changes (RF) of volcanic aerosols are presented in Figure $12 \mathrm{~b}$ for clear sky conditions. These are actually effective flux changes, because model predictions include the dynamical responses. The ULAQ-CCM radiative transfer module [46,54] was set up to compute the tropopause-adjusted RF time series for each eruption considered in this study, both in clear and all sky conditions. Sulfate aerosol Mie scattering data have been computed using refractive properties for a $75 \%$ concentration by weight of sulfuric acid derived from the OPAC database. Significant absorption occurs in the far infrared only between 8 and $18 \mu \mathrm{m}$. As a general result, all sky RFs for both UV-VIS-NIR and planetary infrared are $\sim 60 \%$ of the corresponding clear sky RFs. In turn, the longwave component accounts for $\sim 20 \%$ of the shortwave component in clear sky conditions and $\sim 30 \%$ in all sky conditions. RF occurring during the first 12 months following the Pinatubo eruption has been reported in Hansen et al. [66], as a net-adjusted global annual mean value of $-2.9 \mathrm{~W} / \mathrm{m}^{2}$ at the WMO tropopause for a sulfate optical depth of 0.12 , in clear sky conditions. The corresponding absolute value of the AOD-normalized RF is then 24. In these same conditions, the ULAQ-CCM calculates a quite close normalized RF of 25 .

The time series of the volcanic forcing efficiency for each eruption (i.e., global tropopause RF normalized to global optical thickness) is presented in Figure 13, for both shortwave and longwave components (Figure 13a,b, respectively). The time variability of the RF efficiency is regulated by the magnitude of shortwave and longwave radiative fluxes at the tropopause. The seasonal variability is more pronounced when more volcanic aerosol particles are transported outside the tropics, as in the QBO W shear cases of El Chichón (with aerosol transport towards Northern Hemisphere mid-latitudes) and Agung (towards Southern Hemisphere mid-latitudes) (see Figures 6 and 7). The seasonal variability is significantly less pronounced in the QBO E shear cases (i.e., Ruiz and Pinatubo) with aerosols more confined in the tropical region, where the seasonal cycle of solar radiative fluxes is 
smaller in respect to mid-high latitudes. This is better shown in a compact form in Figure 13c,d, where the variability is measured using the standard deviation of monthly mean values of the RF efficiency, for both shortwave (SW) and longwave (LW) components. This measure gives a factor of 3-6 larger variability in the SW for the QBO W shear cases in terms of the QBO E shear cases, and a factor 1.5-2.5 for the LW. The sensitivity of both SW and LW RF efficiencies to the average effective radius of the volcanic aerosols is presented in Figure 13e,f, showing consistency with the results of Lacis et al. [9] and Hansen $e t$ al. [66]. The slope with $\mathrm{r}_{\text {eff }}$ of the SW RF efficiency from Lacis $e$ t al. [9] appears larger than ours (Figure 13e), with a similar value of $31 \mathrm{Wm}^{-2} / \mathrm{AOD}$ for $\mathrm{r}_{\text {eff }}=0.3 \mu \mathrm{m}$ and $41 \mathrm{Wm}^{-2} / \mathrm{AOD}$ for $\mathrm{r}_{\text {eff }}=0.5 \mu \mathrm{m}$ in Lacis et al. [9], the latter being larger in respect to the $34 \mathrm{Wm}^{-2} /$ AOD calculated in our case. However, the normalized absolute value of the SW RF calculated in Hansen et al. [66] for the Pinatubo case ( $32 \mathrm{Wm}^{-2} / \mathrm{AOD}$, assuming a planetary longwave contribution of $\left.8 \mathrm{Wm}^{-2} / \mathrm{AOD}\right)$ is closer to the ULAQ-CCM value of $34 \mathrm{Wm}^{-2} / \mathrm{AOD}$, with $\mathrm{r}_{\text {eff }}=0.52 \pm 0.10 \mu \mathrm{m}$.
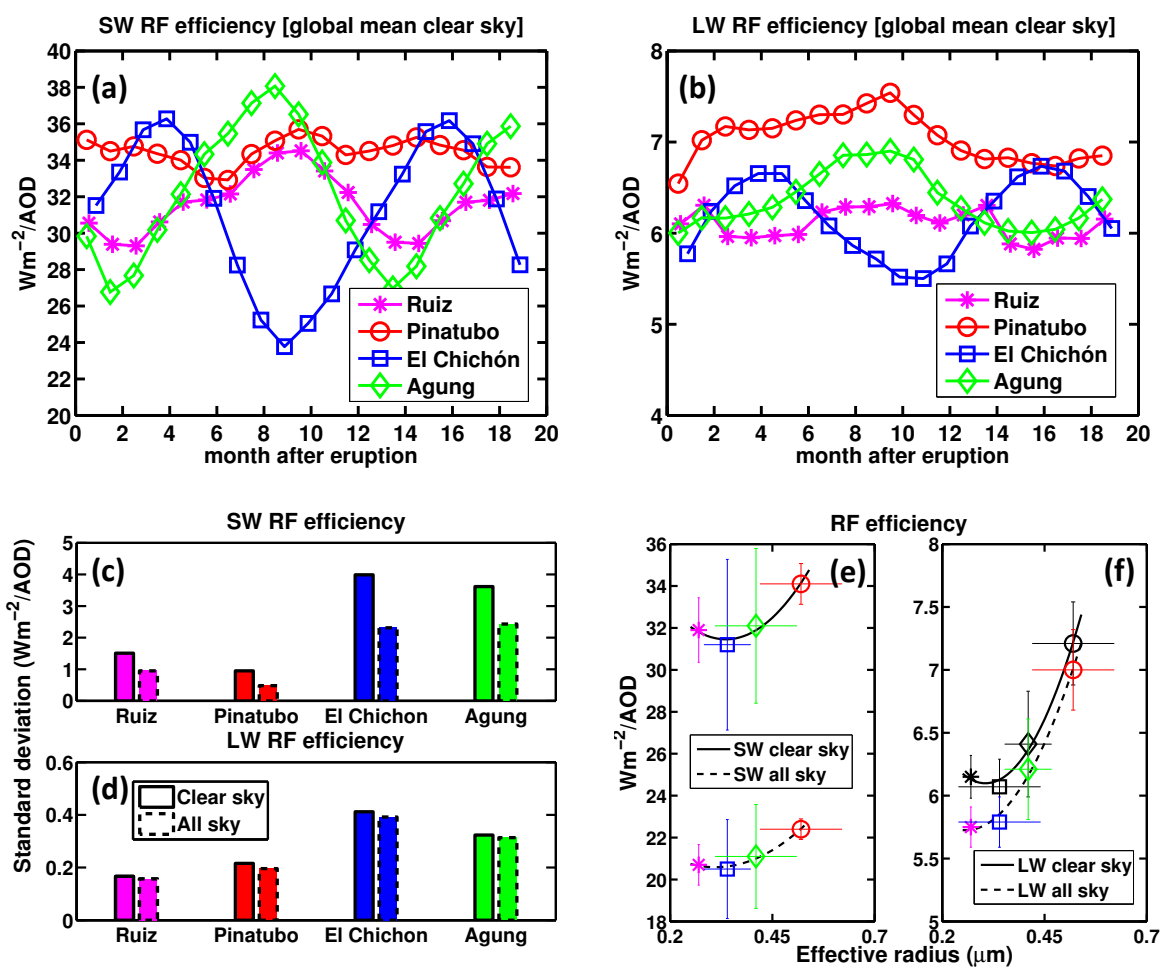

Figure 13. Panel (a) time series of the calculated shortwave RF efficiency, defined as the absolute value of globally averaged SW RF normalized to the volcanic aerosol optical depth ( $\left.\mathrm{Wm}^{-2} / \mathrm{AOD}\right)$. Panel (b) as in (a), but for the longwave RF efficiency. Panel (c) standard deviation of monthly mean values of the SW RF efficiency for Ruiz, Pinatubo, El Chichón and Agung cases, from left to right (Wm $\left.{ }^{-2} / \mathrm{AOD}\right)$. Panel (d) as in (c), but for the LW RF efficiency. Panel (e) average values of the SW RF efficiency, as a function of the volcanic aerosol average effective radius ( $\left.\mathrm{Wm}^{-2} / \mathrm{AOD}\right)$; whiskers denote standard deviation values of monthly mean values of both efficiency and effective radius; the latter increases going from Ruiz, to El Chichón, Agung and finally to Pinatubo. Panel (f) as in (e), but for the LW RF efficiency.

The calculated $e$-folding time of the global-mean volcanic forcing during the first year after the eruptions is also very different between those in $\mathrm{W}$ or $\mathrm{E}$ shear of the QBO. The radiative decay time goes from 9.1 and 8.0 months for El Chichón and Agung, to 28.7 and 24.5 months for Pinatubo and Ruiz, respectively. However, an interesting difference in regards to the mass decay time should be noted: in the RF case, the $e$-folding time after Pinatubo is comparable to that after Ruiz, even though the mass decay time was much shorter (14.6 vs. 30.7 months). The reason is that although the transport pathways are similar in the two cases (both in the QBO easterly phase), the effective radius in the Ruiz 
case is rather constant in time, whereas after Pinatubo it grows to $\sim 0.65 \mu \mathrm{m}$ during the first six months (see Figure 11d): this helps keep the optical thickness at higher values more steadily during the first year after the eruption (see Figure 12a).

\section{Conclusions}

Major volcanic eruptions after 1960 have been considered for the first time in a numerical study conducted with a composition-climate coupled model including an aerosol microphysical code for aerosol formation and growth. For four major eruptions since 1960, we have assessed several metrics of stratospheric dynamics and used these to interpret the effects of transport on the dispersion of the volcanic plumes and assessed the efficiency of the resulting radiative flux changes at the tropopause. The volcanic perturbations show enhanced diabatic heating rates; increased stratospheric temperatures and mean zonal westerly winds; increased planetary wave amplitude; and tropical upwelling. The impact on tropical upwelling is found to be larger for eruptions whereby enhanced aerosol remains confined to the tropics for longer, as tends to be the case in the easterly shear of the quasi-biennial oscillation (QBO; Pinatubo case). Model results are consistent with the mechanism identified by Trepte and Hitchman [24] on the QBO modulation of stratospheric aerosol transport from the tropics, based on satellite observations of aerosol extinction.

The $e$-folding time during the second year after each eruption is rather close among the four considered tropical eruptions (10-12 months), since the coarser particles have already been lost by sedimentation and a significant amount of the aerosol were transported outside the tropics. On the other hand, the $e$-folding time shows considerable variability during the first year, with the largest values for Ruiz and Pinatubo eruptions (E shear of the QBO) contrary to Agung and El Chichón (W shear of the QBO). The University of L'Aquila-Composition-Climate Coupled Model (ULAQ-CCM)-calculated values are approximately 31 and 15 months for Ruiz and Pinatubo, as opposed to 10 and 8 months for Agung and El Chichón, respectively. The time decrease of the global aerosol burden is driven by the particle loss from the stratosphere to the troposphere, where the aerosols are readily removed by wet scavenging. This stratosphere-troposphere exchange is essentially produced on one hand by the gravitational settling of the particles (more efficient for larger radii), and by large-scale transport following the lower branch of the Brewer-Dobson stratospheric circulation on the other. How much of the plume enters the upper or lower branch of the Brewer-Dobson circulation and the degree of isolation of the stratospheric tropical pipe is strongly modulated by the QBO phase. These processes determine that a longer aerosol lifetime is expected during months with an E shear of the equatorial zonal winds (Ruiz and Pinatubo cases), with respect to months with a W shear of the QBO (Agung and El Chichón). For Pinatubo, Ruiz and El Chichón, the model results in terms of tropical upwelling and aerosol dispersal have been successfully evaluated with available data from satellite and lidar observations and from MERRA reanalysis.

The different degree of latitudinal dispersal of the volcanic aerosols during $\mathrm{W}$ or $\mathrm{E}$ shear of the $\mathrm{QBO}$ indirectly affects the temporal evolution of the volcanic RF in the months following the eruptions. Latitudinal and seasonal differences in the magnitude of the solar flux interplay with the differences in dispersion, together determining the efficiency of the volcanic forcing. During QBO W shear cases (e.g., El Chichón and Agung), the plume is rapidly dispersed to mid-latitude where seasonal variations in solar flux reduce volcanic forcing efficiency, whereas for the QBO E shear cases (Pinatubo and Ruiz). A seasonal variation is much less apparent. The aerosol optical depth (AOD)-normalized RFs calculated in this study have been compared with independent estimates from well-tested radiative transfer models $[9,66]$, showing a reasonable consistency in both SW and LW components of the radiative fluxes.

Acknowledgments: The authors acknowledge use of SAGE-II data for aerosol products evaluation. The authors would like to thank the anonymous reviewer for numerous constructive suggestions that have greatly improved the manuscript. 
Author Contributions: Giovanni Pitari: Overall coordination and responsibility for the ULAQ composition-climate model. Glauco Di Genova: Responsibility for the radiative transfer module. Eva Mancini: Setup of the aerosol module for volcanic aerosols. Daniele Visioni: Post-analyses of model results. Ilaria Gandolfi: Setup of the tropospheric $\mathrm{SO}_{\mathrm{x}}$ module. Irene Cionni: Evaluation of model results.

Conflicts of Interest: The authors declare no conflict of interest.

\section{References}

1. Robock, A.; Mao, J. The Volcanic Signal in Surface Temperature Observations. J. Clim. 1995, 8, $1086-1103$. [CrossRef]

2. Kremser, S.; Thomason, L.W.; von Hobe, M.; Hermann, M.; Deshler, T.; Timmreck, C.; Toohey, M.; Stenke, A.; Schwarz, J.P.; Weigel, R.; et al. Stratospheric aerosol-Observations, processes, and impact on climate. Rev. Geophys. 2016. [CrossRef]

3. Solomon, S.; Daniel, J.S.; Neely, R.R., III; Vernier, J.-P.; Dutton, E.G.; Thomason, L.W. The Persistently variable "background" stratospheric aerosol layer and global climate change. Science 2011, 333, 866-870. [CrossRef] [PubMed]

4. Vernier, J.-P.; Thomason, L.W.; Pommerau, J.-P.; Bourassa, A.; Pelon, J.; Garnier, A.; Hauchecorne, A.; Blanot, L.; Trepte, C.; Degenstein, D.; et al. Major influence of tropical volcanic eruptions on the stratospheric aerosol layer during the last decade. Geophys. Res. Lett. 2011, 38, L12807. [CrossRef]

5. Hofmann, D.; Barnes, J.; O’Neill, M.; Trudeau, M.; Neely, R. Increase in background stratospheric aerosol observed with lidar at Mauna Loa Observatory and Boulder, Colorado. Geophys. Res. Lett. 2009, 36, L15808. [CrossRef]

6. Trickl, T.; Giehl, H.; Jäger, H.; Vogelmann, H. 35 year of stratospheric aerosol measurements at Garmisch-Partenkirchen: From Fuego to Eyjafjallajökull, and beyond. Atmos. Chem. Phys. 2013, 13, 5205-5225. [CrossRef]

7. Ridley, D.A.; Solomon, S.; Barnes, J.E.; Burlakov, V.D.; Deshler, T.; Dolgii, S.D.; Herber, A.B.; Nagai, T.; Neely, R.R., III; Nevzorov, A.V.; et al. Total volcanic stratospheric aerosol optical depths and implications for global climate change. J. Geophys. Res. 2014, 41, 7763-7769. [CrossRef]

8. Hansen, J.E.; Lacis, A.; Ruedy, R.; Sato, M. Potential climate impact of Mount Pinatubo eruption. Geophys. Res. Lett. 1992, 19, 215-218. [CrossRef]

9. Lacis, A.; Hansen, J.E.; Sato, M. Climate forcing by stratospheric aerosols. Geophys. Res. Lett. 1992, 19, 1607-1610. [CrossRef]

10. Shindell, D.T.; Schmidt, G.A.; Mann, M.E.; Faluvegi, G. Dynamic winter climate response to large tropical volcanic eruptions since 1600. J. Geophys. Res. 2004, 109, D05104. [CrossRef]

11. Schauffler, S.M.; Daniel, J.S. On the effects of stratospheric circulation changes on trace gas trends. J. Geophys. Res. 1994, 99, 25747. [CrossRef]

12. Dlugokencky, E.J.; Masarie, K.A.; Lang, P.M.; Tans, P.P.; Steele, L.P.; Nisbet, E.G. A dramatic decrease in the growth rate of atmospheric methane in the northern hemisphere during 1992. Geophys. Res. Lett. 1994, 21, 45-48. [CrossRef]

13. Bāndă, N.; Krol, M.; van Weele, M.; van Noije, T.; Röckmann, T. Analysis of global methane changes after the 1991 Pinatubo volcanic eruption. Atmos. Chem. Phys. 2013, 13, 2267-2281. [CrossRef]

14. Bāndă, N.; Krol, M.; van Noije, T.; van Weele, M.; Williams, J.E.; Le Sager, P.; Niemeier, U.; Thomason, L.; Röckmann, T. The effect of stratospheric sulfur from Mount Pinatubo on tropospheric oxidizing capacity and methane. J. Geophys. Res. Atmos. 2015, 120, 1202-1220. [CrossRef]

15. Pitari, G.; Mancini, E. Short-term climatic impact of the 1991 volcanic eruption of Mt. Pinatubo and effects on atmospheric tracers. Nat. Haz. Earth Syst. Sci. 2002, 2, 91-108. [CrossRef]

16. Bluth, G.J.S.; Doiron, S.D.; Schnetzler, C.C.; Krueger, A.J.; Walter, L.S. Global tracking of the $\mathrm{SO}_{2}$ clouds from the June, 1991 Mount Pinatubo eruptions. Geophys. Res. Lett. 1992, 19, 151-154. [CrossRef]

17. Read, W.G.; Froidevaux, L.; Waters, J.W. Microwave limb sounder measurements of stratospheric $\mathrm{SO}_{2}$ from the Mt. Pinatubo volcano. Geophys. Res. Lett. 1993, 20, 1299-1302. [CrossRef]

18. Russell, P.B.; Livingston, J.M.; Pueschel, R.F.; Bauman, J.J.; Pollack, J.B.; Brooks, S.L.; Hamill, P.; Thomason, L.W.; Stowe, L.L.; Deshler, T.; et al. Global to microscale evolution of the Pinatubo volcanic aerosol derived from diverse measurements and analyses. J. Geophys. Res. 1996, 101, 18745-18763. [CrossRef] 
19. Dhomse, S.S.; Emmerson, K.M.; Mann, G.W.; Bellouin, N.; Carslaw, K.S.; Chipperfield, M.P.; Hommel, R.; Abraham, N.L.; Telford, P.; Braesicke, P.; et al. Aerosol microphysics simulations of the Mt. Pinatubo eruption with the UM-UKCA composition-climate model. Atmos. Chem. Phys. 2014, 14, 11221-11246. [CrossRef]

20. Hofmann, D.J.; Rosen, J.M. Sulfuric acid droplet formation and growth in the stratosphere after the 1982 eruption of El Chichón. Science 1983, 222, 325-327. [CrossRef] [PubMed]

21. McCormick, M.P.; Veiga, R.E. SAGE II measurements of early Pinatubo aerosols. Geophys. Res. Lett. 1992, 19, 155-158. [CrossRef]

22. Lambert, A.; Grainger, R.G.; Remedios, J.J.; Rodgers, C.D.; Corney, M.; Taylor, F.W. Measurements of the evolution of the Mt. Pinatubo aerosol cloud by ISAMS. Geophys. Res. Lett. 1993, 20, 1287-1290. [CrossRef]

23. Long, C.S.; Stowe, L.L. Using the NOAA/AVHRR to study stratospheric aerosol optical thickness following the Mt. Pinatubo eruption. Geophys. Res. Lett. 1994, 21, 2215-2218. [CrossRef]

24. Trepte, C.R.; Hitchman, M.H. Tropical stratospheric circulation deduced from satellite aerosol data. Nature 1992, 355, 626-628. [CrossRef]

25. McCormick, M.P.; Thomason, L.W.; Trepte, C.R. Atmospheric effects of the Mt. Pinatubo eruption. Nature 1995, 373, 399-404. [CrossRef]

26. Pitari, G. A numerical study of the possible perturbation of stratospheric dynamics due to Pinatubo aerosols: Implications for tracer transport. J. Atmos. Sci. 1993, 50, 2443-2461. [CrossRef]

27. Prather, M.J. Catastrophic loss of stratospheric ozone in dense volcanic clouds. J. Geophys. Res. 1992, 97, 10187-10191. [CrossRef]

28. Fahey, D.W.; Kawa, S.R.; Woodbridge, E.L.; Tin, P.; Wilson, J.C.; Jonsson, H.H.; Dye, J.E.; Baumgardner, D.; Borrmann, S.; Toohey, D.W.; et al. In-situ measurements constraining the role of sulphate aerosols in mid-latitude ozone depletion. Nature 1993, 363, 509-514. [CrossRef]

29. Pitari, G.; Rizi, V. An estimate of the chemical and radiative perturbation of stratospheric ozone following the eruption of Mt. Pinatubo. J. Atmos. Sci. 1993, 50, 3260-3276. [CrossRef]

30. Kinne, S.; Toon, O.B.; Prather, M.J. Buffering of stratospheric circulation by changing amounts of tropical ozone: A Pinatubo case study. Geophys. Res. Lett. 1992, 19, 1927-1930. [CrossRef]

31. Labitzke, K.; McCormick, M.P. Stratospheric temperature increases due to Pinatubo aerosols. Geophys. Res. Lett. 1992, 19, 207-210. [CrossRef]

32. Grant, W.B.; Fishman, J.; Browell, E.V.; Brackett, V.G.; Nganga, D.; Minga, A.; Cros, B.; Veiga, R.E.; Butler, C.F.; Fenn, M.A.; et al. Observations of reduced ozone concentrations in the tropical stratosphere after the eruption of Mt. Pinatubo. Geophys. Res. Lett. 1992, 19, 1109-1112. [CrossRef]

33. Schoeberl, M.R.; Bhartia, P.K.; Hilsenrath, E. Tropical ozone loss following the eruption of Mt. Pinatubo. Geophys. Res. Lett. 1993, 20, 29-32. [CrossRef]

34. Telford, P.; Braesicke, P.; Morgenstern, O.; Pyle, J. Reassessment of causes of ozone column variability following the eruption of Mount Pinatubo using a nudged CCM. Atmos. Chem. Phys. 2009, 9, 4251-4260. [CrossRef]

35. Soden, B.J.; Wetherald, R.T.; Stenchikov, G.L.; Robock, A. Global cooling after the eruption of Mount Pinatubo: A test of climate feedback by water vapor. Science 2002, 296, 727-730. [CrossRef] [PubMed]

36. Dunkerton, T.J.; Delisi, D.P. Anomalous temperature and zonal wind in the tropical upper stratosphere, 1982/83. J. Geophys. Res. 1991, 96, 22631-22641. [CrossRef]

37. Stenchikov, G.L.; Kirchner, I.; Robock, A.; Graf, H.-F.; Antuna, J.C.; Grainger, R.; Lambert, A.; Thomason, L. Radiative forcing from the 1991 Mt. Pinatubo volcanic eruption. Geophys. Res. 1998, 103, 13837-13858. [CrossRef]

38. Kirchner, I.; Stenchikov, G.L.; Graf, H.-F.; Robock, A.; Antuna, J.C. Climate model simulation of winter warming and summer cooling following the 1991 Mount Pinatubo volcanic eruption. J. Geophys. Res. 1999, 104, 19039-19055. [CrossRef]

39. Young, R.E.; Houben, H.; Toon, O.B. Radiatively forced dispersion of the Mt. Pinatubo volcanic cloud and induced temperature perturbations in the stratosphere during the first few months following the eruption. Geophys. Res. Lett. 1994, 21, 369-372. [CrossRef]

40. Fairlie, T.D.A. Three-dimensional transport simulations of the dispersal of volcanic aerosol from Mount Pinatubo. Q.J.R. Meteorol. Soc. 1995, 121, 1943-1980. [CrossRef]

41. Timmreck, C.; Graf, H.-F.; Kirchner, I. A one and half year interactive MA/ECHAM4 simulation of Mt. Pinatubo aerosol. J. Geophys. Res. 1999, 104, 9337-9359. [CrossRef] 
42. Niemeier, U.; Timmreck, C.; Graf, H.-F.; Kinne, S.; Rast, S.; Self, S. Initial fate of fine ash and sulfur from large volcanic eruptions. Atmos. Chem. Phys. 2009, 9, 9043-9057. [CrossRef]

43. Aquila, V.; Oman, L.D.; Stolarski, R.S.; Colarco, P.R.; Newman, P.A. Dispersion of the volcanic sulfate cloud from a Mount Pinatubo-like eruption. J. Geophys. Res. 2012, 117. [CrossRef]

44. Aquila, V.; Oman, L.D.; Stolarski, R.S.; Douglass, A.R.; Newman, P.A. The response of ozone and nitrogen dioxide to the eruption of Mount Pinatubo at southern and northern midlatitudes. J. Atmos. Sci. 2013, 70, 894-900. [CrossRef]

45. Aquila, V.; Garfinkel, C.; Oman, L.D.; Waugh, D. Modifications of the QBO by perturbations of the stratospheric aerosol layer. Geophys. Res. Lett. 2014, 41, 1738-1744. [CrossRef]

46. Pitari, G.; Aquila, V.; Kravitz, B.; Robock, A.; Watanabe, S.; Cionni, I.; De Luca, N.; Di Genova, G.; Mancini, E.; Tilmes, S. Stratospheric Ozone Response to Sulfate Geoengineering: Results from the Geoengineering Model Intercomparison Project (GeoMIP). J. Geophys. Res. 2014, 119, 2629-2653. [CrossRef]

47. Pitari, G.; Mancini, E.; Rizi, V.; Shindell, D.T. Impact of future climate and emission changes on stratospheric aerosols and ozone. J. Atmos. Sci. 2002, 59, 414-440. [CrossRef]

48. Eyring, V.; Butchart, N.; Waugh, D.W.; Akiyoshi, H.; Austin, J.; Bekki, S.; Bodeker, G.E.; Boville, B.A.; Bruhl, C.; Chipperfield, M.P.; et al. Assessment of temperature, trace species, and ozone in chemistry-climate model simulation of the recent past. J. Geophys. Res. 2006, 111, D22308. [CrossRef]

49. Sander, S.P.; Friedl, R.R.; Barker, J.R.; Golden, D.M.; Kurylo, M.J.; Wine, P.H.; Abbatt, J.P.D.; Burkholder, J.B.; Kolb, C.E.; Moortgat, G.K.; et al. Chemical Kinetics and Photochemical Data for Use in Atmospheric Studies, Evaluation No. 17; JPL Publication 10-6; Jet Propulsion Laboratory, California Institute of Technology: Pasadena, CA, USA; 10; June; 2011.

50. Chipperfield, M.P.; Liang, Q.; Strahan, S.E.; Morgenstern, O.; Dhomse, S.S.; Abraham, N.L.; Archibald, A.T.; Bekki, S.; Braesicke, P.; Di Genova, G.; et al. Multi-model Estimates of Atmospheric Lifetimes of Long-lived Ozone-Depleting Substances: Present and Future. J. Geophys. Res. 2014, 119, 2555-2573. [CrossRef]

51. Randles, C.A.; Kinne, S.; Myhre, G.; Schulz, M.; Stier, P.; Fischer, J.; Doppler, L.; Highwood, E.; Ryder, C.; Harris, B.; et al. Intercomparison of shortwave radiative transfer schemes in global aerosol modeling: Results from the AeroCom Radiative Transfer Experiment. Atmos. Chem. Phys. 2013, 13, 2347-2379. [CrossRef]

52. Morgenstern, O.; Giorgetta, M.A.; Shibata, K.; Eyring, V.; Waugh, D.; Shepherd, T.G.; Akiyoshi, H.; Austin, J.; Baumgärtner, A.; Bekki, S.; et al. A review of CCMVal-2 models and simulations. J. Geophys. Res. 2010, 115, D00M02. [CrossRef]

53. Pitari, G.; Di Genova, G.; De Luca, N. A modelling study of the impact of on-road diesel emissions on Arctic black carbon and solar radiation transfer. Atmosphere 2015, 6, 318-340. [CrossRef]

54. Pitari, G.; Di Genova, G.; Coppari, E.; De Luca, N.; Di Carlo, P.; Iarlori, M.; Rizi, V. Desert dust transported over Europe: Lidar observations and model evaluation of the radiative impact. J. Geophys. Res. 2015, 120, 2881-2898. [CrossRef]

55. Eyring, V.; Lamarque, J.-F.; Hess, P.; Arfeuille, F.; Bowman, K.; Chipperfield, M.P.; Duncan, B.; Fiore, A.; Gettelman, A.; Giorgetta, M.A.; et al. Overview of IGAC/SPARC Chemistry-Climate Model Initiative (CCMI) Community Simulations in Support of Upcoming Ozone and Climate Assessments. SPARC Newsl. 2013, 40, 48-66.

56. Sato, M.; Hansen, J.E.; McCormick, M.P.; Pollack, J.B. Stratospheric aerosol optical depth, 1850-1990. J. Geophys. Res. 1993, 98, 22987-22994. [CrossRef]

57. McCormick, M.P.; Thomason, L. Collection of Global Profiles of Aerosol Extinction, Temperature, Ozone, Nitrogen Dioxide and Water Vapour as part of the Stratospheric Aerosol and Gas Experiment II (SAGE II). NCAS British Atmospheric Data Centre 2006. Available online: http://catalogue.ceda.ac.uk/uuid/ bd5e5f99d8f789324698379efba64502 (accessed on 21 January 2016).

58. Uppala, S.M.; KÅllberg, P.W.; Simmons, A.J.; Andrae, U.; Da Costa Bechtold, V.; Fiorino, M.; Gibson, J.K.; Haseler, J.; Hernandez, A.; Kelly, G.A.; et al. The ERA-40 re-analysis. Q. J. R. Meteorol.Soc. 2005, 131, 2961-3012. [CrossRef]

59. Free, M.; Seidel, D.J.; Angell, J.K.; Lanzante, J.; Durre, I.; Peterson, T.C. Radiosonde Atmospheric Temperature Products for Assessing Climate (RATPAC): A new data set of large-area anomaly time series. J. Geophys. Res. 2005, 110, D22101. [CrossRef]

60. Jäger, H.; Hofmann, D. Midlatitude lidar backscatter to mass, area, and extinction conversion model based on in situ aerosol measurements from 1980 to 1987. Appl. Opt. 1991, 30, 127-138. [CrossRef] [PubMed] 
61. Rienecker, M.M.; Suarez, M.J.; Gelaro, R.; Todling, R.; Bacmeister, J.; Liu, E.; Bosilovich, M.G.; Schubert, S.D.; Takacs, L.; Kim, G.-K.; et al. MERRA: NASA's Modern-Era Retrospective Analysis for Research and Applications. J. Clim. 2011, 24, 3624-3648. [CrossRef]

62. Ray, E.A.; Moore, F.L.; Rosenlof, K.L.; Davis, S.M.; Sweeney, C.; Tans, P.; Wang, T.; Elkins, J.W.; Bönisch, H.; Engel, A.; et al. Improving stratospheric transport trend analysis based on $\mathrm{SF}_{6}$ and $\mathrm{CO}_{2}$ measurements. J. Geophys. Res. 2014, 119. [CrossRef]

63. Strahan, S.E.; Douglass, A.R.; Stolarski, R.S.; Akiyoshi, H.; Bekki, S.; Braesicke, P.; Butchart, N.; Chipperfield, M.P.; Cugnet, D.; Dhomse, S.; et al. Using transport diagnostics to understand Chemistry Climate Model ozone simulations. J. Geophys. Res. 2011, 116, D17302. [CrossRef]

64. Weisenstein, D.; Bekki, S.; Pitari, G.; Timmreck, C.; Mills, M. Modeling of stratospheric aerosols. In SPARC Assessment of Stratospheric Aerosol Properties; Thomason, L., Peter, T., Eds.; WCRP-124, WMO/TD-1295, SPARC report No 4; Chapter 6.

65. Thomason, L.W.; Poole, L.R.; Deshler, T. A global climatology of stratospheric aerosol surface area density deduced from Stratospheric Aerosol and Gas Experiment II measurements: 1984-1994. J. Geophys. Res. 1997, 102, 8967-8976. [CrossRef]

66. Hansen, J.E.; Sato, M.; Ruedy, R.; Nazarenko, L.; Lacis, A.; Schmidt, G.A.; Russell, G.; Aleinov, I.; Bauer, M.; Bauer, S.; et al. Efficacy of climate forcings. J. Geophys. Res. 2005, 110, D18104. [CrossRef]

(C) 2016 by the authors; licensee MDPI, Basel, Switzerland. This article is an open access article distributed under the terms and conditions of the Creative Commons Attribution (CC-BY) license (http://creativecommons.org/licenses/by/4.0/). 